\title{
Topographic Data Requirements for EOS Global Change Research
}

By Dean B. Gesch

Open-File Report 94-626 


\title{
TOPOGRAPHIC DATA REQUIREMENTS FOR EOS GLOBAL CHANGE RESEARCH
}

\author{
By Dean B. Gesch ${ }^{1}$
}

\section{PREFACE}

This document is a result of Earth Observing System Data and Information System (EOSDIS) Version 0 activities of the Land Processes Distributed Active Archive Center at the U.S. Geological Survey's EROS Data Center. A relatively small part of the Version 0 funding provided by NASA is used to address topographic data issues related to EOS. These issues include identifying and improving access to existing sources of topographic data, data generation, facilitating the use of topographic data in global change research by demonstrating derivative products, and inventorying the specific topographic data requirements of EOS investigators.

There is a clear need for global topographic data in EOSDIS. Only 10 percent of the global land surface is covered by high-resolution data that are available to the global change science community. Alternative sources for new data exist or have been proposed; however, none of them alone can fulfill the data requirements by the launch of the first EOS platform in 4 years. There is no operational provider of all the source data that are required. Even if appropriate global source data existed, a concerted production effort would be necessary to ensure the existence of the requisite topographic data before EOS launch. Additionally, no funding from NASA or any other agency has been appropriated for a new mapping mission or for other means of data acquisition.

This effort to document requirements is an initial step toward understanding the severity of the data shortage. It is well beyond the scope of Version 0 funding and capabilities to provide the required data in the proper timeframe. The shortage of data and the lack of a plan for providing the necessary topographic data through EOSDIS in time for launch are issues that must be addressed by the EOS program.

${ }^{1}$ Hughes STX Corporation. Work performed under U.S. Geological Survey contract 1434-92C-40004.

Any use of trade, product, or firm names is for descriptive purposes only and does not imply endorsement by the U.S. Government. 


\section{CONTENTS}

PREFACE

1.0 Introduction

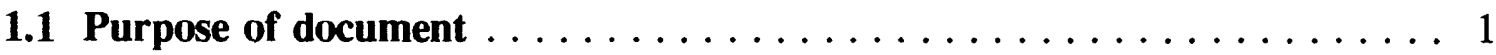

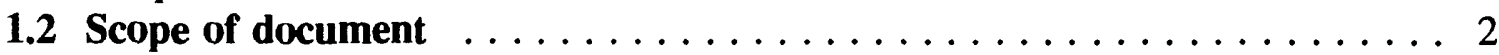

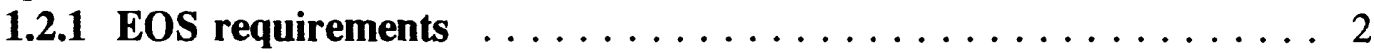

1.2.2 Status of existing topographic data $\ldots \ldots \ldots \ldots \ldots \ldots \ldots 2$

1.2.3 Alternatives for topographic data generation $\ldots \ldots \ldots \ldots 2$

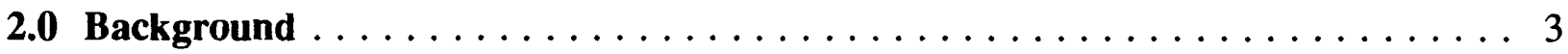

2.1 General requirements statements $\ldots \ldots \ldots \ldots \ldots \ldots \ldots \ldots \ldots \ldots$

2.1.1 U.S. Global Change Research Program ............. 3

2.1.2 International Geosphere-Biosphere Program ........... 3

2.1.3 Committee on Earth Observation Satellites ........... 3

2.1.4 Global Energy and Water Cycle Experiment ........... 4

2.1.5 National Research Council .................. 4

2.2 NASA Topographic Science Working Group $\ldots \ldots \ldots \ldots \ldots$

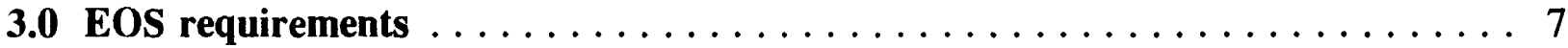

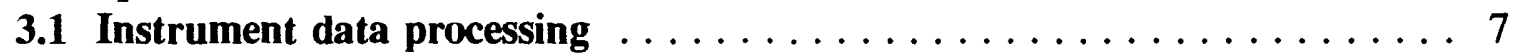

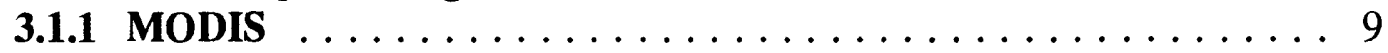

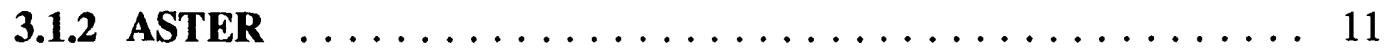

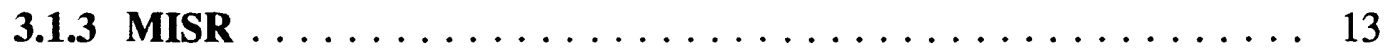

3.1.4 Other instruments $\ldots \ldots \ldots \ldots \ldots \ldots \ldots \ldots \ldots \ldots \ldots$

3.2 Interdisciplinary science investigations $\ldots \ldots \ldots \ldots \ldots \ldots \ldots \ldots \ldots$

3.3 Effect of data unavailability $\ldots \ldots \ldots \ldots \ldots \ldots \ldots \ldots \ldots$

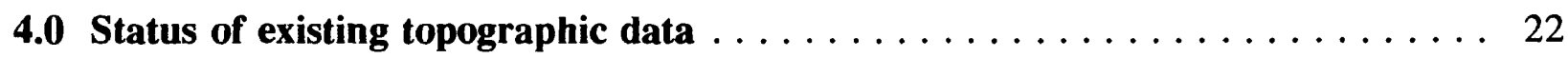

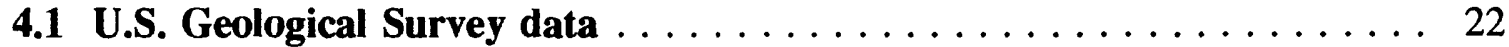

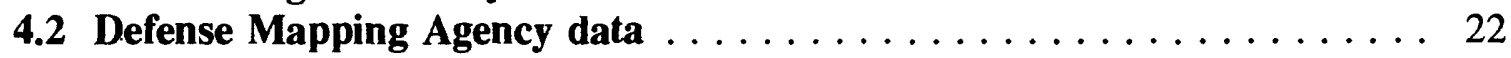

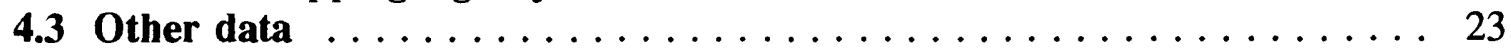

5.0 Alternatives for topographic data generation $\ldots \ldots \ldots \ldots \ldots \ldots \ldots \ldots$

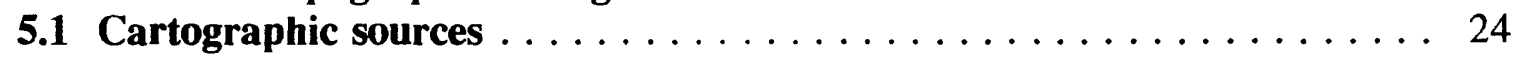

5.1.1 Digital Chart of the World $\ldots \ldots \ldots \ldots \ldots \ldots \ldots \ldots 24$

5.1.2 Vector Smart Map .................... 25

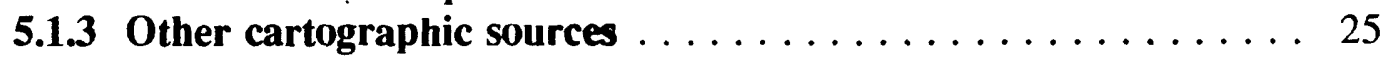

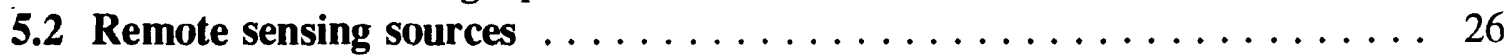

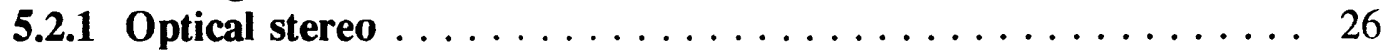

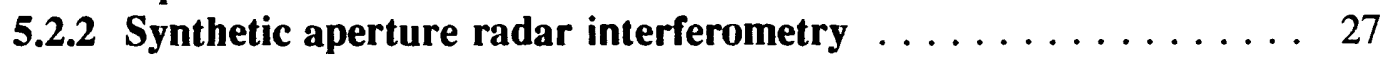

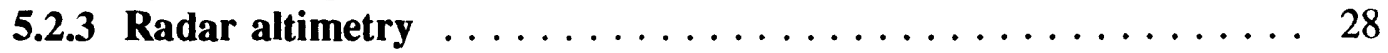

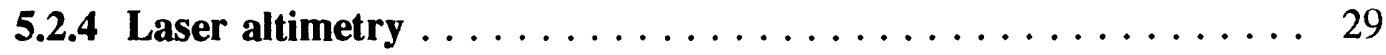




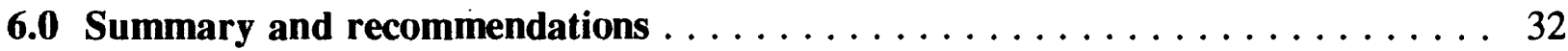

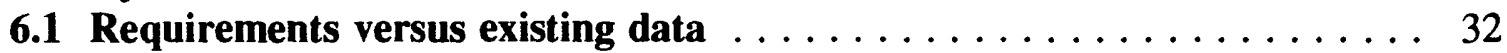

6.2 Requirements versus future sources $\ldots \ldots \ldots \ldots \ldots \ldots \ldots \ldots \ldots \ldots$

6.3 Topics requiring further study $\ldots \ldots \ldots \ldots \ldots \ldots \ldots \ldots \ldots \ldots$

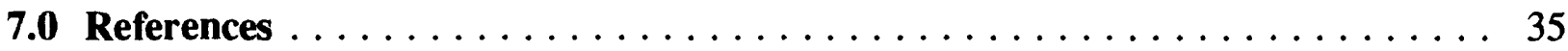

Appendix 8.1 Accuracy reporting for topographic data . . . . . . . . . . . 39

Appendix 8.2 Digital Elevation Model product description $\ldots \ldots \ldots \ldots \ldots \ldots 43$

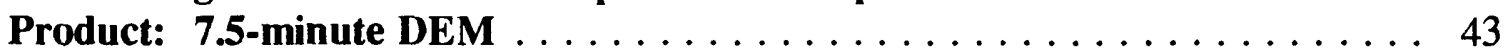

Product: 7.5 -minute Alaska DEM $\ldots \ldots \ldots \ldots \ldots \ldots \ldots \ldots \ldots \ldots \ldots$

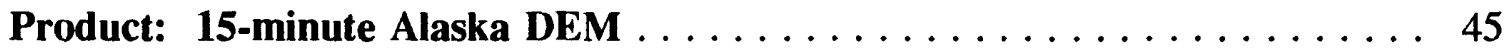

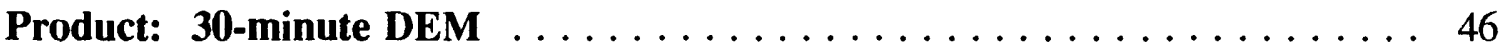

Product: 1-degree DEM $\ldots \ldots \ldots \ldots \ldots \ldots \ldots \ldots \ldots \ldots \ldots \ldots \ldots$

Appendix 8.3 Digital Terrain Elevation Data product description $\ldots \ldots \ldots \ldots \ldots 48$

Product: DTED level $1 \ldots \ldots \ldots \ldots \ldots \ldots \ldots \ldots \ldots \ldots$

Appendix 8.4 Digital Chart of the World product description . . . . . . . . . . . 49

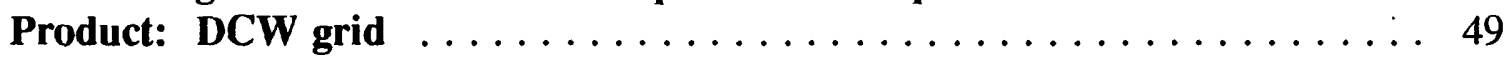

Appendix 8.5 Sources and characteristics of optical stereo data $\ldots \ldots \ldots \ldots$

Appendix 8.6 USGS topographic data research activities $\ldots \ldots \ldots \ldots \ldots$

Appendix 8.7 Distribution of topographic data $\ldots \ldots \ldots \ldots \ldots \ldots \ldots \ldots$ 


\section{TABLES}

Page

Table 2.2-1. Topographic data requirements from NASA/ASI joint topographic working group $\ldots \ldots \ldots \ldots \ldots \ldots \ldots \ldots \ldots \ldots \ldots \ldots \ldots \ldots \ldots \ldots \ldots$

3.1-1. Sensor parameters for MODIS, ASTER, and MISR. $\ldots \ldots \ldots \ldots \ldots$

3.1.1-1. Elevation (in meters) that causes 1-pixel displacement in MODIS data, and the percentage of the Earth's surface higher than that specified

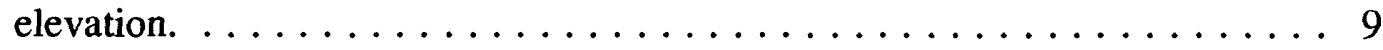

3.1.1-2. Topographic data requirements for MODIS processing. $\ldots \ldots \ldots \ldots 11$

3.1.2-1. Elevation (in meters) that causes 1-pixel displacement in ASTER data, and the percentage of the Earth's surface higher than that specified

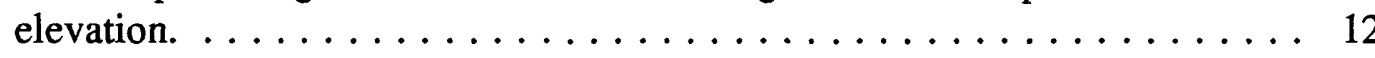

3.1.2-2. Vertical precision (relative accuracy) required to maintain $5^{\circ}$ slope

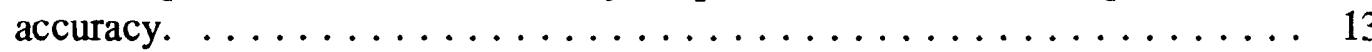

3.1.3-1. Elevation (in meters) that causes 1-pixel displacement in MISR data from off-nadir cameras, and the percentage of the Earth's surface higher than that specified elevation. . . . . . . . . . . . . . . 14

3.1.4-1. Topographic data requirements for CERES, AIRS, and EOSP. . . . . 15

3.2-1. IDS teams that have specified topographic data as required input. . . . . 16

3.2-2. Topographic data requirements of IDS teams. . . . . . . . 17

3.2-3. USGCRP science priorities. The science elements and subtopics listed in italics are those for which topographic data have been identified as

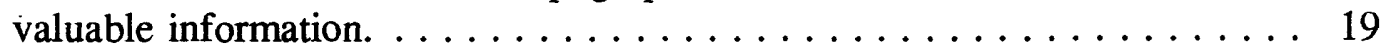

3.3-1. Selected data products (produced with topographic data) required by IDS teams.

5-1. Comparison of methods for measuring terrain heights by satellite remote

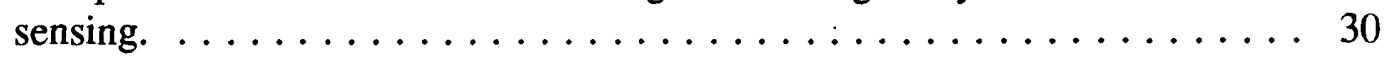

5-2. Current and future sources of digital topographic data. . . . . . . 31

8.5-1. Sources and characteristics of satellite data for topographic mapping. . . . 56 


\section{ILLUSTRATIONS}

Page

Figure 3.3-1. Algorithm dependency among some MODIS, ASTER, and MISR

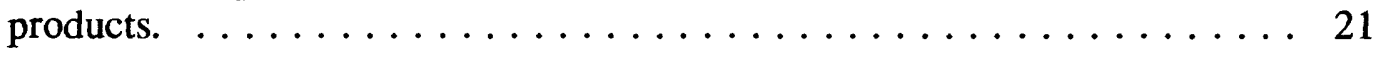

8.1-1. Diagram of hypothetical terrain surface and corresponding elevation model 41 


\subsection{Introduction}

Researchers investigating global change often require topographic data because many of the physical processes being studied are controlled by topography. Additionally, many of the remote sensing products used in characterizing global change need significant processing to be useful for quantitative analysis, and these corrections (atmospheric, radiometric, and geometric) rely on knowledge of the topography.

The general need for topographic data has been previously documented, and the many applications of digital topographic data are well published in the scientific literature. However, the needs for detailed global topographic data continue to increase. The advanced space-based sensors of NASA's Earth Observing System (EOS) and the ambitious scientific goals of the various global change research programs continue to drive the development of topographic data generation.

\subsection{Purpose of Document}

The U.S. Geological Survey's EROS Data Center (EDC) serves as one of the Distributed Active Archive Centers (DAAC) in the EOS Data and Information System (EOSDIS). In its role as the Land Processes DAAC (LPDAAC), EDC is responsible for managing data related to land processes. The function of the LPDAAC is to produce, archive, and distribute data for EOS research on global land processes. In support of the EOSDIS Version 0 implementation, the LPDAAC is acquiring and archiving existing earth resources data sets, both remotely sensed and ancillary, and making them available to EOS researchers for algorithm and model development in the prelaunch stage of the EOS program.

The overall objective of the LPDAAC Version 0 topographic project is to develop improved access to suitable digital topographic data for EOS research. A preliminary phase of this activity is documenting the topographic data requirements of the EOS investigators. Previous requirements statements have not been specific enough, especially regarding the EOS instruments and science investigations, so the purpose of this document is to record as quantitatively as possible the specific EOS requirements. The document will aid in planning and setting priorities for acquiring, processing, and generating global topographic data. Thus, this document should help meet the goals of improving data accessibility and facilitating topographic data use in scientific applications.

The contents of this document represent the current knowledge of both EOS requirements and topographic data sources. Requirements for instrument data processing, as well as interdisciplinary science (IDS) investigations, will undoubtedly become better defined as the prelaunch period of the EOS program progresses. Also, new sources of topographic data will most likely emerge, and innovative, more efficient techniques for generating data from existing sources also will be developed. 


\subsection{Scope of Document}

\subsubsection{EOS Requirements}

Topographic data requirements for EOS are the focus of this document. These requirements can be subdivided into two categories: data for instrument product generation, and data for IDS investigators to use in modeling physical processes. The LPDAAC is responsible for generating land surface products from data collected by the Advanced Spaceborne Thermal Emission and Reflection Radiometer (ASTER) and the Moderate-Resolution Imaging Spectroradiometer (MODIS). Land related products will also be generated from Multi-Angle Imaging Spectro-Radiometer (MISR) data at the Langley Research Center DAAC. Other instruments that have topographic data requirements are the Atmospheric Infrared Sounder (AIRS), the Clouds and Earth's Radiant Energy System (CERES), and the Earth Observing Scanning Polarimeter (EOSP). Resolution, accuracy, and coverage are the critical characteristics of digital topographic data specified in a requirements statement. As important as the requirement statement itself is the rationale behind it. The basis for the requirement helps determine the impact on science if the required data are unavailable.

\subsubsection{Status of Existing Topographic Data}

Existing global topographic data do not fulfill the requirements imposed by EOS. However, some of the requirements are met for certain areas of the land surface that are covered by high-quality data. Knowing the characteristics of existing data helps to judge their value for use in scientific applications.

\subsubsection{Alternatives for Topographic Data Generation}

To meet the known data requirements, several sources for topographic data generation are available, and they are classified as either cartographic or remote sensing sources. These sources, which vary in availability and stage of development, produce topographic data of varying quality, but they are all important as options for meeting the stated needs. 


\subsection{Background}

\subsection{General Requirements Statements}

As the study of environmental change becomes more focused on global-scale processes, numerous forums have recognized the need for many types of geographically referenced spatial data with global coverage. Topographic information has been identified in many cases as being essential for studying processes relevant to global change.

\subsubsection{U.S. Global Change Research Program}

The U.S. Global Change Research Program (USGCRP) involves nine Federal agencies. The Committee on Earth and Environmental Sciences (CEES) coordinates USGCRP activities. In a CEES (1992) report, "The U.S. Global Change Data and Information Management Program Plan," topography (absolute height) was listed as a land surface parameter having "high importance" for documenting and understanding global change. Surface structure (slope and aspect) was listed as having "substantial importance." The lack of global coverage for both of these parameters was noted.

\subsubsection{International Geosphere-Biosphere Program}

The land cover working group of the International Geosphere-Biosphere Program (IGBP) has recommended the creation of a global data set with 1-kilometer resolution, derived from Advanced Very High Resolution Radiometer (AVHRR) data. The data set would be useful for studying land processes related to global change. The proposal to create such a data set is described in the report "Improved Global Data for Land Applications" (IGBP, 1992). The procedures recommended in this report require topographic data to produce surface reflectance images through radiometric calibration and atmospheric correction. First-order corrections, such as a Rayleigh scattering correction, which compensate for gross changes in elevation that cause variation in atmospheric transmittance and scattering, require only general elevation models. However, correction on a pixel-by-pixel basis of localized radiometric and atmospheric effects, such as those caused by slope and aspect, requires elevation models with much higher resolution and accuracy. Geometric correction is also an important requirement. In areas of high relief, topographic data are needed for terrain correction so that images from different orbits can be precisely coregistered to minimize misregistration errors in the compositing process.

\subsubsection{Committee on Earth Observation Satellites}

The Committee on Earth Observation Satellites (CEOS) has recognized the importance of topographic data and has begun efforts on several fronts. The CEOS Working Group on Data has established an Auxiliary Data Subgroup, and that subgroup has drafted a proposal for a global elevation model with 1-kilometer resolution (Schreier and Muller, 1992). The Global Land One-Kilometer Baseline Elevation (GLOBE) project proposal lists the various applications in which topographic data are essential, and it also notes the absence of a global 
data set at the specified resolution.

The CEOS Working Group on Calibration/Validation has established the Terrain Mapping Subgroup to address the issues of mapping terrain heights from remote sensing satellites. At its first meeting in December 1992, held at the Jet Propulsion Laboratory (JPL), the subgroup recommended greater emphasis on generating high-resolution digital elevation models (DEM) (1.5-meter vertical accuracy and 5-meter horizontal accuracy). Such DEM's would allow topographic mapping at a scale of 1:50,000, which would meet the requirements of most applications (CEOS, 1992).

\subsubsection{Global Energy and Water Cycle Experiment}

The World Climate Research Program (WCRP) has established the Global Energy and Water Cycle Experiment (GEWEX) to better understand regional and global water and energy budgets. This large effort entails developing and coupling improved macroscale atmospheric and hydrologic models. In the GEWEX science plan, topography and its derivatives, such as slope, are recognized as being critical elements for the data base used for model development (WCRP, 1991).

\subsubsection{National Research Council}

The National Research Council has recently reported on the status of multidisciplinary hydrologic science (Committee on Opportunities in the Hydrologic Sciences, 1991). Included in its report is a discussion of data collection, distribution, and analysis. Topography was identified as the most important surface factor affecting hydrologic processes. The same report notes that data accurate enough for quantitative modeling are available for only a small part of the global land surface and that appropriate data for the polar ice sheets also are lacking.

\subsection{NASA Topographic Science Working Group}

In 1988, NASA's Topographic Science Working Group produced an important document that describes the diverse scientific applications of topographic data, summarizes existing data, describes the techniques for acquiring new data, and makes recommendations for producing a global topographic data set (Topographic Science Working Group, 1988). This report provides an invaluable source of information on how topographic data are used to study physical processes.

The requirements in this report are expressed as a range of scales. A global data set of moderate resolution (approximately 1,000-meter horizontal resolution and 10- to 100-meter vertical resolution) is identified as a first requirement. This global data set should be supplemented by a regional data set with higher resolution (100-meter horizontal and 1- to 10 -meter vertical). Local sites would require very high resolution data (10-meter horizontal, 0.1 - to 1 -meter vertical). 
A major point in the report is that data with high vertical accuracy are essential. Many of the topographic variables, such as slope, aspect, and slope length, useful for studying regional and local scale processes are derived from local differences reflected in the DEM. Any noise in the DEM will be emphasized by the differencing operations used to calculate these variables, thereby reducing their usefulness. This concept has been extended in the use of slope resolution as a measure of the quality of elevation data (Harding, 1992). Slope resolution characterizes the uncertainty of the surface slope calculated from adjacent elevations in the DEM. Thus, slope between adjacent DEM elevations cannot be calculated with any greater accuracy than that specified by the slope resolution. For study of slope-dependent processes, such as surface runoff or local energy flux, slope resolution, which is a function of the vertical precision (relative accuracy) of the data, is the critical element determining the value of a topographic data set. Even if a topographic data set has very high horizontal resolution, its utility will be significantly limited if it has poor vertical precision (large relative errors). When scientific requirements for elevation data are specified or the capabilities of a data collection system are described, the vertical precision and horizontal resolution must be considered together, because their combination defines the attainable slope resolution.

The 1988 NASA report also notes the critical need for topographic data of the Greenland and Antarctic ice sheets. Data with greater vertical and horizontal accuracy are needed for studies of ice dynamics and mass balance.

The scale of required data (global, regional, or local) and the mapping repeat interval are specified for many of the disciplines described in the report. Also listed are the remote sensing technologies that can collect data having the required characteristics for specific applications. The technologies considered are stereo optical, laser altimetry, narrow-beam scanning radar altimetry, wide-beam radar altimetry, and synthetic aperture radar (SAR) interferometry. An overall recommendation in the report is that acquiring a consistent global topographic data set should be a high priority for NASA. Such a data set should be acquired by using a combination of radar altimetry, laser altimetry (for polar regions), and radar interferometry.

NASA has continued its working group activities by participating in a joint topographic working group with the Italian Space Agency (ASI). This group has met several times to document and evaluate options for a mission to map global topography. A multibeam laser altimeter (MBLA) and an interferometric SAR are two instruments being considered. The group has also informally surveyed scientists of various disciplines to compile a list of requirements. Their responses are summarized in table 2.2-1. These requirements are estimates and many of them have not yet been substantiated by field or simulation experiments or by model dependent testing. 
Table 2.2-1. Topographic data requirements from NASA/ASI joint topographic working group

\begin{tabular}{|c|c|c|c|c|c|c|c|}
\hline \multirow{2}{*}{ APPLICATION } & \multicolumn{2}{|c|}{ MAXIMUM } & \multicolumn{2}{|c|}{ MINIMUM } & \multirow{2}{*}{$\mathbf{A} / \mathbf{P}$} & \multirow{2}{*}{ Cov } & \multirow{2}{*}{ FRQ } \\
\hline & VERT. & HORIZ. & VERT. & HORIZ. & & & \\
\hline \multicolumn{8}{|l|}{ HYDROLOGY } \\
\hline Global water balance & 5 & 200 & 20 & 5,000 & A & $G$ & 0 \\
\hline Catchment routing & 1 & 50 & 5 & 500 & $\mathbf{A}$ & $\mathbf{R}$ & 0 \\
\hline Functional relationship models & 0.5 & 10 & 1 & 100 & $\mathbf{P}$ & $\mathbf{R}$ & 0 \\
\hline Snow accumulation & 0.4 & 10 & 1 & 80 & A & $\mathbf{R}$ & 0.3 \\
\hline Finite element models & 0.1 & 8 & 0.6 & 20 & $\mathbf{P}$ & $\mathrm{L}$ & 0 \\
\hline Wetland circulation & 0.1 & 100 & 0.2 & 100 & A & $\mathbf{R}$ & 0 \\
\hline \multicolumn{8}{|l|}{ ECOLOGY } \\
\hline Life zones & 5 & 1,000 & 10 & 5,000 & $\mathbf{A}$ & $\mathbf{R}$ & 0 \\
\hline Hillslope position & 0.5 & 10 & 1 & 60 & $\mathrm{P}$ & $\mathrm{L}$ & 0 \\
\hline Wetland dynamics & 0.05 & 100 & 0.1 & 700 & $\mathbf{A}$ & $\mathbf{R}$ & 5 \\
\hline \multicolumn{8}{|l|}{ GEOMORPHOLOGY } \\
\hline Tectonic provinces & 40 & 2,000 & 100 & 10,000 & $\mathbf{A}$ & $G$ & 0 \\
\hline Mountain ranges & 8 & 200 & 50 & 5,000 & $\mathbf{A}$ & G & 0 \\
\hline Large valley systems & 1 & 70 & 8 & 500 & A & $\mathbf{R}$ & 0 \\
\hline Hillslope \& stream morphology & 0.5 & 10 & 1 & 70 & $\mathrm{P}$ & $\mathrm{L}$ & 0 \\
\hline Dunes & 0.2 & 5 & 1 & 10 & $\mathbf{P}$ & $\mathrm{L}$ & 1 \\
\hline \multicolumn{8}{|l|}{ GLACIOLOGY } \\
\hline Glacial moraines & 0.1 & 10 & 1 & 100 & $\mathrm{P}$ & $\mathbf{R}$ & 0 \\
\hline Alpine glaciers & 0.1 & 10 & 1 & 50 & $\mathbf{P}$ & $\mathrm{L}$ & 0 \\
\hline Ice sheets & 0.08 & 500 & 0.5 & 1,000 & A & $\mathbf{R}$ & 1 \\
\hline \multicolumn{8}{|l|}{ GEOLOGY / GEOPHYSICS } \\
\hline Gravity / magnetics & 1 & 200 & 80 & 10,000 & A & G & 0 \\
\hline Plate boundaries & 1 & 200 & 8 & 2,000 & A & $G$ & 0 \\
\hline Marine geology & 0.1 & 2,000 & 0.2 & 10,000 & A & $\mathbf{G}$ & 0 \\
\hline Structural geology & 0.1 & 10 & 1 & 1,000 & A & $\mathbf{R}$ & 0 \\
\hline Fault zone tectonics & 0.1 & 10 & 2 & 100 & $\mathbf{P}$ & $\mathrm{L}$ & 0 \\
\hline Flow \& ash volumes & 0.2 & 7 & 2 & 20 & A & $\mathbf{R}$ & 5 \\
\hline Volcanic swelling & 0.1 & 20 & 1 & 200 & A & $\mathbf{R}$ & 1 \\
\hline Volcano morphology & 1 & 20 & 10 & 500 & $\mathbf{P}$ & $\mathbf{R}$ & 0 \\
\hline
\end{tabular}

LEGEND:

MAXIMUM: Highest resolution required (in meters)

MINIMUM: $\quad$ Lowest resolution acceptable (in meters)

A/P: $\quad$ Most important data characteristic, Accuracy (reference to an absolute datum) or Precision (relative accuracy within

COV: $\quad$ Coverage required (Global, Regional, or Local)

FRQ: $\quad$ Frequency ( 0 - only once; numerical value - years between observations) 


\subsection{EOS Requirements}

EOS is NASA's main contribution to the USGCRP. EOS is composed of a series of remote sensing satellites, an associated data and information system, and a global change research program. The long-term global observations made by EOS sensors will enable the assessment of hydrologic, biogeochemical, climatological, and geophysical processes (Asrar and Dokken, 1993). Such observations will lead to a greater understanding of fundamental physical processes and the interactions among them.

Topographic data requirements for EOS can be divided into two categories: data needed for instrument product generation and data needed by IDS investigators for modeling physical processes. The use of topographic data and its derivatives will be pervasive throughout EOSDIS because six EOS instrument teams have identified a need for topographic data to produce standard products. Four of these instruments will be launched on the first EOS platform in 1998. Additionally, 13 of the 29 IDS principal investigators have listed topographic data as required for their investigations. The requirements in these two categories of instrument data processing and IDS investigations are described in detail in the following sections.

The requirements reported here were derived from various sources. Information was gathered by electronic mail and telephone contact with instrument teams and IDS teams, by LPDAAC personnel attending instrument team meetings and IDS reviews, and from other EOS forums and documents. The report "Earth Observing System Output Data Products and Input Requirements - Version 2.0" (SPSO, 1992) provided a good baseline of information about the data requirements of the instrument and IDS teams.

\subsection{Instrument Data Processing}

Topographic data are required for processing EOS sensor data to generate data products. Geometric, radiometric, and atmospheric corrections require knowledge of the elevation and terrain characteristics, such as slope and aspect, of the land surface. The interrelated nature of EOS sensor observations and the way in which those observations are applied in interdisciplinary investigations compound the importance of topographic data. For example, a particular higher level data product, such as leaf area index, may not require topographic data to be produced,. but calibrated data from individual EOS sensors used as input for the generation of that higher level product do require corrections based on topography. This "algorithm dependency" propagates the effect of ancillary data through the process of level 3 and level 4 product generation. In a worst case scenario, the lack of topographic information required for atmospheric and radiometric preprocessing would preclude the generation of higher level products, because the input sensor data cannot be calibrated to the proper degree of accuracy.

The EOS Investigators Working Group (IWG) has recognized that part of the process of defining high-priority EOS data products includes identifying intermediate data that are 
required to produce measurements of critical environmental variables (levels 2, 3, and 4 products) (Moore and Dozier, 1992). By examining the method used to measure environmental variables and identifying the required intermediate data, scientists can estimate the effects of limited data availability and make recommendations for modifications to the EOSDIS data acquisition plan. Thus, the IWG has recommended that for each proposed EOS data product, the scientific requirement for its production must be clearly stated, the reasons for the specified data quality must be given, and the data required for its production must be described.

Products characterizing the land surface will be generated at the LPDAAC from MODIS and ASTER data. MISR data constitute another source that will be processed to generate landrelated data products. Current plans call for all MISR products to be generated at the Langley Research Center DAAC. Many of these land products require topographic data as input. ASTER and MISR will have the capability of generating elevation data that may be helpful in meeting the requirements for producing other EOS standard products. However, dependence on ASTER and MISR as primary sources of elevation data would have certain consequences for EOS data acquisition and processing. Stereo ASTER and MISR images would have to be collected and processed into DEM's before the generation of any other products that require the elevation data as input. Details on the characteristics of MODIS, ASTER, and MISR are found in table 3.1-1.

Table 3.1-1. Sensor parameters for MODIS, ASTER, and MISR

\begin{tabular}{|c|c|c|c|c|c|}
\hline Sensor & $\begin{array}{c}\text { Spectral } \\
\text { bands }\end{array}$ & $\begin{array}{c}\text { Pixel size } \\
\text { (meters) }\end{array}$ & $\begin{array}{l}\text { Field of view } \\
\text { (degrees) }\end{array}$ & $\begin{array}{l}\text { Swath width } \\
(\mathrm{km})\end{array}$ & $\begin{array}{l}\text { Maximum } \\
\text { repeat cycle } \\
\text { (days) }\end{array}$ \\
\hline \multirow{3}{*}{ MODIS } & 2 & 250 & \multirow{3}{*}{$\begin{array}{c} \pm 55 \\
\text { cross track }\end{array}$} & \multirow{3}{*}{2,300} & \multirow{3}{*}{2} \\
\hline & 5 & 500 & & & \\
\hline & 29 & 1,000 & & & \\
\hline \multirow{3}{*}{ ASTER } & 3 & 15 & $\begin{array}{c} \pm 24 \\
\text { cross track }\end{array}$ & \multirow{3}{*}{60} & \multirow{3}{*}{16} \\
\hline & 6 & 30 & \multirow{2}{*}{$\begin{array}{c} \pm 8.5 \\
\text { cross track }\end{array}$} & & \\
\hline & 5 & 90 & & & \\
\hline \multirow{4}{*}{ MISR } & \multirow{4}{*}{$4 *$} & 250 (nadir) & \multirow{4}{*}{$\begin{array}{c} \pm 70.5 \\
\text { along track }\end{array}$} & \multirow{4}{*}{364} & \multirow{4}{*}{9} \\
\hline & & 275 & & & \\
\hline & & 550 & & & \\
\hline & & 1,100 & & & \\
\hline
\end{tabular}

* Four bands for each of nine cameras for a total of 36 channels 


\subsubsection{MODIS}

MODIS is the primary EOS sensor for collecting global data to study the vegetation dynamics of the Earth's land surface. Many of the land products that will be generated from MODIS data require topographic data, either directly or indirectly. Topographic data requirements for MODIS have been relatively well documented compared to those for other EOS instruments. Although the list of MODIS products to be generated at launch is currently under review, the 1992 SPSO report listed 14 MODIS products that had topographic data specified as direct input. The 14 products were grouped into the MODIS algorithm categories of bidirectional reflectance, directional reflectance, georadiance corrections, land cover and land cover change, and surface roughness.

Topography will affect the geometric characteristics of MODIS data by causing relief displacement of pixels. Relief displacement becomes more pronounced as scan angle increases or pixel resolution increases. Simulations of the effect of topography on MODIS data using the ETOPO5 representation of global topography (National Geophysical Data Center, 1988) have shown that approximately 25 percent of the global land surface will induce a terrain relief displacement error of greater than 1 pixel for MODIS 1-kilometer pixels. For MODIS 250-meter pixels, almost 60 percent of the land surface has elevation sufficient to cause a 1-pixel displacement (Muller and Eales, 1990). The relief displacement is less at nadir and small scan angles; thus, much higher relief is required to produce a 1pixel shift. However, it is important to correct pixels at all scan angles, because data from the entire MODIS field of view $\left( \pm 55^{\circ}\right)$ will be processed. Table 3.1.1-1 lists the elevation that will cause a displacement equal to 1 pixel for various MODIS scan angles. Also listed is the percentage of the global land surface that would cause such a displacement.

Table 3.1.1-1. Elevation (in meters) that causes 1-pixel displacement in MODIS data, and the percentage of the Earth's surface higher than that specified elevation

\begin{tabular}{|c|c|c|c|c|c|c|c|c|c|c|}
\hline \multirow{3}{*}{$\begin{array}{c}\begin{array}{c}\text { Pixel size } \\
\text { (meters) }\end{array} \\
250 \\
\end{array}$} & \multicolumn{10}{|c|}{ Off-nadir scan angle (degrees) } \\
\hline & \multicolumn{2}{|c|}{ \pm 10} & \multicolumn{2}{|c|}{ \pm 20} & \multicolumn{2}{|c|}{$\pm \mathbf{3 0}$} & \multicolumn{2}{|c|}{ \pm 40} & \multicolumn{2}{|c|}{$\pm \mathbf{5 0}$} \\
\hline & 1,319 & $34 \%$ & 706 & $48 \%$ & 530 & $55 \%$ & 477 & $58 \%$ & 501 & $57 \%$ \\
\hline 500 & 2,639 & $18 \%$ & 1,412 & $32 \%$ & 1,060 & $39 \%$ & 954 & $41 \%$ & 1,003 & $40 \%$ \\
\hline 1,000 & 5,281 & $<1 \%$ & 2,826 & $13 \%$ & 2,122 & $24 \%$ & 1,910 & $26 \%$ & 2,008 & $25 \%$ \\
\hline
\end{tabular}

Terrain correction, or the removal of relief displacement, to create an orthoimage requires the use of a DEM during image resampling. Analysis has shown that a DEM grid spacing of twice the nadir pixel size is required to perform appropriate terrain correction (Muller, 1993). For MODIS, this results in a requirement for elevation data with horizontal grid spacings of $500,1,000$, and 2,000 meters for 250-, 500-, and 1,000-meter pixels, respectively. Many of 
the MODIS land products will be used for multitemporal analysis in which highly accurate coregistration is imperative. Terrain correction using accurate DEM's helps achieve the required coregistration quality.

An analysis of the factors contributing to MODIS geolocation error included an examination of the impact of uncertain terrain height information (Hubanks and Fleig, 1993). Many factors affect the error in the calculated location of a MODIS pixel, including uncertainty about the sensor's position and attitude. The accuracy of topographic data used to reference the elevation for a given Earth location also affects the overall error. The vertical error of a DEM causes error in overall geolocation in the cross-track direction, and as the scan angle increases, the geolocation error due to DEM error increases. At a scan angle of about $40^{\circ}$, the geolocation error and the DEM error reach a one-to-one correspondence, (1 meter of DEM error leads to 1 meter of geolocation error). At the maximum scan angle of $55^{\circ}$, an elevation measurement with a 650-meter error (which is the stated accuracy for the Digital Chart of the World data base, see section 5.1.1 and appendix 8.4) results in a geolocation error of 1,423 meters. Comparatively, an elevation measurement in error by 100 meters would cause a geolocation error of 219 meters. An elevation accuracy of 30 meters (typical of the Digital Terrain Elevation Data produced by the Defense Mapping Agency, see section 4.2 and appendix 8.3) leads to a geolocation error of 66 meters.

Geolocation error also can be expressed as a fraction of a pixel (relative geolocation error) (Hubanks and Fleig, 1993). For example, a 100-meter vertical error in elevation data leads to a maximum relative geolocation error of more than 5 percent of a 1,000-meter pixel at a scan angle of $42^{\circ}$. Comparatively, a 30-meter vertical error in elevation data causes a geolocation error of less than 2 percent of a pixel for all scan angles. Although a global elevation data set with such vertical accuracy does not exist, this analysis points out the improvements in calculated Earth locations of MODIS pixels if highly accurate data are used for geolocation processing.

Topography will significantly affect the radiometric properties of MODIS data. Atmospheric and radiometric corrections to remove these topographic effects are essential for MODIS products being used in multitemporal studies, especially vegetation indexes, land cover products, and surface temperature products. Different levels of radiometric correction lead to varying requirements for topographic data, and the goal is accurate retrieval of "at surface reflectance." The first level of correction adjusts the atmospheric path length caused by gross changes in elevation. More detailed corrections account for localized topographic effects such as illumination differences caused by slope and aspect, reflection from adjacent terrain, and sub-pixel shadowing (Teillet and Staenz, 1993). These pixel-by-pixel corrections, especially those that account for subpixel phenomena, require highly accurate topographic data with grid spacing finer than that of the image itself. The radiometric processing requirements for MODIS 250- and 500-meter pixels would be met by a global DEM with 100-meter horizontal grid spacing, 30-meter vertical accuracy, and a slope accuracy of $1^{\circ}$ to $3^{\circ}$. For 1-kilometer MODIS pixels, a global DEM with 500-meter grid spacing, 100-meter vertical accuracy, and $5^{\circ}$ slope accuracy is required (Running, 1993). The topographic data requirements for 
MODIS processing are summarized in table 3.1.1-2.

Table 3.1.1-2. Topographic data requirements for MODIS processing

\begin{tabular}{|c|c|c|c|c|}
\hline \multicolumn{2}{|c|}{ Process } & $\begin{array}{l}\text { Grid spacing } \\
\text { (meters) }\end{array}$ & $\begin{array}{l}\text { Vertical accuracy } \\
\text { (meters) }\end{array}$ & $\begin{array}{l}\text { Slope accuracy } \\
\text { (degrees) }\end{array}$ \\
\hline \multirow{3}{*}{$\begin{array}{l}\text { Orthoimage } \\
\text { generation }\end{array}$} & $250 \mathrm{~m}$ pixel & 500 & -- & \\
\hline & $500 \mathrm{~m}$ pixel & 1,000 & -- & \\
\hline & $\begin{array}{c}1,000 \mathrm{~m} \\
\text { pixel }\end{array}$ & 2,000 & -- & \\
\hline \multirow{3}{*}{$\begin{array}{l}\text { Radiometric } \\
\text { correction }\end{array}$} & $250 \mathrm{~m}$ pixel & 100 & 30 & $1-3$ \\
\hline & $500 \mathrm{~m}$ pixel & 100 & 30 & $1-3$ \\
\hline & $\begin{array}{c}1,000 \mathrm{~m} \\
\text { pixel }\end{array}$ & 500 & 100 & 5 \\
\hline \multicolumn{2}{|c|}{ Geolocation } & -- & 30 & \\
\hline
\end{tabular}

The accuracy of slopes measured from a DEM is an important consideration for higher order radiometric correction of MODIS data. The slope accuracy depends on the vertical precision and the horizontal grid spacing of a digital topographic data set (Harding, 1992; see appendix 8.1). Vertical precision is the point-to-point or relative vertical accuracy within a particular data set. Slope accuracy, or slope resolution, assumes a worst case scenario that adjacent elevation grid points used to calculate slope are both in error by the maximum specified vertical precision, but the errors are opposite in sign. A vertical precision of 5.2 meters is required to meet the MODIS $3^{\circ}$ slope accuracy specification for a DEM with a spacing of 100 meters. Calculating slopes to an accuracy of $5^{\circ}$ with a 500 -meter grid DEM requires a vertical precision of 43.7 meters.

A major activity of the MODIS land products group will be algorithm development and product validation over specific test sites. Current plans call for a network of some 60 global test sites, each about 100 by 100 kilometers. Multiresolution imagery data sets will be assembled for each site. High-resolution, accurate topographic data will also be an important data layer for these areas.

\subsubsection{ASTER}

ASTER will provide several high-resolution geophysical data sets of the land surface. The multispectral, high spatial resolution data will be an important complement to other coarser resolution sensors on board the EOS-AM1 platform. Several factors contribute to ASTER requirements for topographic data: the design of the sensor itself, its off-nadir imaging capability, and the high spatial resolution output products that measure phenomena influenced 
by topography, such as surface radiances and temperatures.

The 1992 SPSO report listed eight ASTER products that had specified topographic data as direct input. These eight products were listed under the algorithm categories of surface radiance, land surface brightness temperature, land emissivity and kinetic temperature, and geological and mineral mapping. The list of standard ASTER products to be generated at launch is under review and is not yet final.

ASTER is a unique sensor in that its visible and near infrared (VNIR), short wavelength infrared (SWIR), and thermal infrared (TIR) bands are collected by three separate radiometer subsystems. This configuration leads to a requirement for coregistration as part of level 1B2 product generation. The bands will be registered between each telescope. Additionally, the SWIR bands require within-telescope registration. The individual SWIR detectors are spaced far enough apart that slight parallax between bands will result. The current SWIR band-toband registration specification calls for an accuracy of 0.2 pixels between bands. Elevation data with an accuracy of about 500 meters are required to ensure that SWIR band coregistration meets specifications.

ASTER will be able to point off-nadir (cross track) up to $\pm 8.55^{\circ}$ for the SWIR and TIR bands and up to $\pm 24^{\circ}$ for the VNIR bands. This off-nadir viewing geometry causes geometric distortions in higher relief areas. The terrain relief distortions must be removed by using a digital elevation model to create planimetrically correct products. Table 3.1.2-1 lists the elevation that would cause a 1-pixel displacement (a planimetric error equal to 1 pixel) for several ASTER look angles. Also listed is the percentage of the global land surface that would cause such a displacement. The angles of $2.4^{\circ}, 10.9^{\circ}$, and $25.9^{\circ}$ represent the approximate look angle at the edge of a 60 -kilometer swath centered at nadir, $8.55^{\circ}$, and $24^{\circ}$ off-nadir, respectively.

Table 3.1.2-1. Elevation (in meters) that causes 1-pixel displacement in ASTER data, and the percentage of the Earth's surface higher than that specified elevation

\begin{tabular}{|c|c|c|c|c|c|c|c|}
\hline \multirow{3}{*}{$\begin{array}{c}\begin{array}{c}\text { Sensor } \\
\text { subsystem }\end{array} \\
\text { VNIR } \\
\end{array}$} & \multirow{3}{*}{$\begin{array}{c}\begin{array}{c}\text { Pixel size } \\
\text { (meters) }\end{array} \\
15\end{array}$} & \multicolumn{6}{|c|}{ Look angle (degrees) } \\
\hline & & \multicolumn{2}{|c|}{ \pm 2.4} & \multicolumn{2}{|c|}{ \pm 10.9} & \multicolumn{2}{|c|}{ \pm 25.9} \\
\hline & & 323 & $68 \%$ & 73 & $94 \%$ & 35 & $97 \%$ \\
\hline SWIR & 30 & 646 & $5(1) \%$ & 146 & $85 \%$ & & \\
\hline TIR & 90 & 1,938 & $26 \%$ & 437 & $61 \%$ & & \\
\hline
\end{tabular}

Radiometric calibration and atmospheric correction of ASTER data must take into account the influences of topography. As with MODIS, different levels of correction will be required. A general knowledge of the base elevation is necessary to adjust the atmospheric path length, but a more detailed representation of the topography is required to account for local 
illumination differences. Procedures currently employed require knowledge of the slope to within $\pm 5^{\circ}$ for slopes less than $20^{\circ}$ (Morrison, 1993). This accuracy allows for a 3-percent error specification for calculated radiances to be met. Table 3.1.2-2 shows the vertical precision required to meet a $5^{\circ}$ slope accuracy specification for grid spacings equal to the ASTER pixel sizes.

Table 3.1.2-2. Vertical precision (relative accuracy) required to maintain $5^{\circ}$ slope accuracy.

\begin{tabular}{|c|c|}
\hline $\begin{array}{c}\text { Grid spacing } \\
\text { (meters) }\end{array}$ & $\begin{array}{c}\text { Vertical precision } \\
\text { (meters) }\end{array}$ \\
\hline \hline 15 & 1.3 \\
\hline 30 & 2.6 \\
\hline 90 & 7.9 \\
\hline
\end{tabular}

ASTER stereo images collected with the VNIR subsystem are suitable for generating highly accurate DEM's if ground control is available (Schier, 1993). The advantage of this is that, if the topographic data required for correcting a certain scene are not available, they can be generated from the stereo VNIR band. This is appealing because the derived DEM is intrinsically registered to the ASTER data. This scenario has definite implications for ASTER product generation. The DEM would have to be generated first before any other higher level product could be created, and DEM generation is currently a labor- and computer-intensive process.

\subsubsection{MISR}

Several important land surface products, including bidirectional reflectances, will be generated from MISR data, and these products will be used by other instrument teams and IDS teams to generate higher level products. Six MISR products are listed in the SPSO report under the algorithm heading "retrieval of land surface properties."

The geometric correction requirements for MISR data are similar to those for MODIS data. The pixel displacements for some MISR data will be even more severe than those for MODIS data because MISR will collect data with look angles up to $\pm 70.5^{\circ}$. Table 3.1.3-1 lists the elevation that will cause a displacement equal to 1 pixel for the MISR view angles. Also listed is the percentage of the global land surface that would cause such a displacement. Additionally, MISR data are collected through nine separate cameras, and removal of terrain effects is important for coregistration. The MISR level 1B2 product will be resampled with a digital elevation model, thus producing a terrain-corrected product. 
Table 3.1.3-1. Elevation (in meters) that causes 1-pixel displacement in MISR data from offnadir cameras, and the percentage of the Earth's surface higher than that specified elevation

\begin{tabular}{|c|c|c|c|c|c|c|c|c|}
\hline \multirow{3}{*}{$\begin{array}{c}\begin{array}{c}\text { Pixel size } \\
\text { (meters) }\end{array} \\
275 \\
\end{array}$} & \multicolumn{8}{|c|}{ Off-nadir view angle (degrees) } \\
\hline & \multicolumn{2}{|c|}{ \pm 26.1} & \multicolumn{2}{|c|}{ \pm 45.6} & \multicolumn{2}{|c|}{ \pm 60} & \multicolumn{2}{|c|}{ \pm 70.5} \\
\hline & 491 & $57 \%$ & 211 & $79 \%$ & 78 & $93 \%$ & 5 & $>99 \%$ \\
\hline 550 & 982 & $41 \%$ & 422 & $62 \%$ & 157 & $83 \%$ & 10 & $>99 \%$ \\
\hline 1,100 & 1,965 & $26 \%$ & 844 & $44 \%$ & 313 & $69 \%$ & 20 & $>99 \%$ \\
\hline
\end{tabular}

Digital elevation models are required initially for the geolocation of MISR data. The accuracy of the geolocation is critical to ensure proper alignment of the MISR image and the DEM. This alignment is necessary for the removal of topographic effects to allow accurate camera-to-camera coregistration. For the nadir camera, using of a DEM with vertical accuracy of 60 meters results in a geolocation error of up to 6 percent. A DEM with 30meter vertical accuracy is required to maintain the same level of geolocation error for offnadir cameras (Diner, 1993). If DEM's with such an accuracy level are unavailable, the proposed MISR registration process will have to be changed to meet the specification, which will cause a significant increase in computation and reliance on other ancillary information.

The MISR team also requires knowledge of the land surface slopes for retrieval of surface radiation parameters. DEM's with grid spacing (and corresponding position errors) of 100 to 200 meters should allow for slope determination to the required degree of accuracy. Thus, MISR's overall requirements for topographic data for geolocation, registration, and slope knowledge would be met by an elevation data base having 100-meter grid spacing and 30meter vertical accuracy.

\subsubsection{Other Instruments}

Topographic data have been listed as required input by three other EOS instrument teams. Product generation for CERES, AIRS, and EOSP requires relatively coarse-resolution topographic data, and the data requirements are summarized in table 3.1.4-1. Products for cloud retrieval, atmospheric fluxes, surface fluxes, and flux divergence will be generated from CERES data. The vertical accuracy of topographic data is important for the remote sensing of clouds by CERES because the land surface is the lower boundary used in retrieval algorithms. An accurate land and water mask is also required for determining if a given pixel is located over land or water. In addition to being on the EOS-AM1 platform, the CERES instrument will also be on board the Tropical Rainfall Measuring Mission (TRMM) to be launched in 1997; therefore the product-generation algorithms that will employ topographic data need to be ready sooner than other EOSDIS product-generation systems. 
Table 3.1.4-1. Topographic data requirements for CERES, AIRS, and EOSP

\begin{tabular}{|c|c|c|c|c||}
\hline \hline Instrument & $\begin{array}{c}\text { EOS platform } \\
\text { \& launch date }\end{array}$ & $\begin{array}{c}\text { Grid spacing } \\
\text { (kilometers) }\end{array}$ & $\begin{array}{c}\text { Vertical } \\
\text { accuracy } \\
\text { (meters) }\end{array}$ & Coverage \\
\hline \hline CERES & AM1 / 1998 & 10 & $50-100$ & global \\
\hline AIRS & PM1 / 2000 & $10-20$ & $50-100$ & global \\
\hline EOSP & AM2 / 2003 & 20 & 100 & global \\
\hline
\end{tabular}

AIRS is a passive infrared spectrometer that will collect data for the retrieval of atmospheric temperature and humidity profiles. Topographic data will be used as auxiliary data for generating AIRS level 2 products. Surface pressure, a key parameter for the retrieval algorithms, can be estimated from the elevation data when reliable surface pressure data are unavailable. Product generation from AIRS data also requires the percentages of land and water within the 15-kilometer footprint of the sensor. EOSP data will be processed for the retrieval of aerosol information. The land surface elevation is needed to account for the amount of Rayleigh scattering by the atmosphere (which is air mass dependent).

\subsection{Interdisciplinary Science Investigations}

Besides the indirect requirement that they have for topographic data through the use of EOS instrument products, the IDS teams have specific requirements for topographic data and derivatives as input to physical process models. The Solid Earth Panel of the EOS Investigators Working Group has noted that "topography is perhaps the single most important land surface characteristic that determines the climatic, hydrologic, and geomorphic regimes" (Isacks and Mouginis-Mark, 1992). The interdisciplinary nature of studying the processes that affect global climatic change is a major reason why a global topographic data base is needed. The Solid Earth Panel also recognized the need to increase access to existing data, and it endorsed the acquisition of new data with current and planned remote sensing missions.

Out of the total of 29 teams, 13 IDS teams have identified topographic data as required input. Not surprisingly, the required resolution, accuracy, and coverage vary widely because they reflect the diversity of the scientific investigations. Table 3.2-1 lists the principal investigator and investigation title for each IDS team that has identified a requirement. The type of products required include topographic elevation, land surface roughness, ice sheet elevation, topographic slope, and volcano elevation. Table 3.2-2 summarizes the IDS topographic data requirements. For the products with a global, regional, and local distinction in coverage, several teams indicated requirements in more than one category. The values shown for grid spacing and accuracy indicate the range of specified requirements. 
Table 3.2-1. IDS teams that have specified topographic data as required input

\begin{tabular}{|c|c|}
\hline Principal investigator & Investigation title \\
\hline Barron & Global Water Cycle: Extension Across the Earth Sciences \\
\hline Batista / Richey & $\begin{array}{l}\text { Long-Term Monitoring of the Amazon Ecosystems through EOS: From } \\
\text { Patterns to Processes }\end{array}$ \\
\hline Cihlar & Northern Biosphere Observation and Modeling Experiment \\
\hline Dickinson & $\begin{array}{l}\text { NCAR Project to Interface Modeling on Global and Regional Scales } \\
\text { with EOS Observations }\end{array}$ \\
\hline Dozier & $\begin{array}{l}\text { Hydrology, Hydrochemical Modeling, and Remote Sensing in } \\
\text { Seasonally Snow-Covered Alpine Drainage Basins }\end{array}$ \\
\hline Isacks & $\begin{array}{l}\text { Climate, Erosion, and Tectonics in the Andes and Other Mountain } \\
\text { Systems }\end{array}$ \\
\hline Kerr / Sorooshian & $\begin{array}{l}\text { The Hydrologic Cycle and Climatic Processes in Arid and Semi-Arid } \\
\text { Lands }\end{array}$ \\
\hline Lau & Global Hydrologic Processes and Climate \\
\hline Moore & Changes in Biogeochemical Cycles \\
\hline Mouginis-Mark & $\begin{array}{l}\text { A Global Assessment of Active Volcanism, Volcanic Hazards, and } \\
\text { Volcanic Inputs to the Atmosphere from EOS }\end{array}$ \\
\hline Sellers & Biosphere-Atmosphere Interactions \\
\hline Simard & $\begin{array}{c}\text { Use of a Cryospheric System (CRYSYS) to Monitor Global Change in } \\
\text { Canada }\end{array}$ \\
\hline Wielicki & $\begin{array}{c}\text { An Interdisciplinary Investigation of Clouds and Earth's Radiant } \\
\text { Energy System: Analysis }\end{array}$ \\
\hline
\end{tabular}




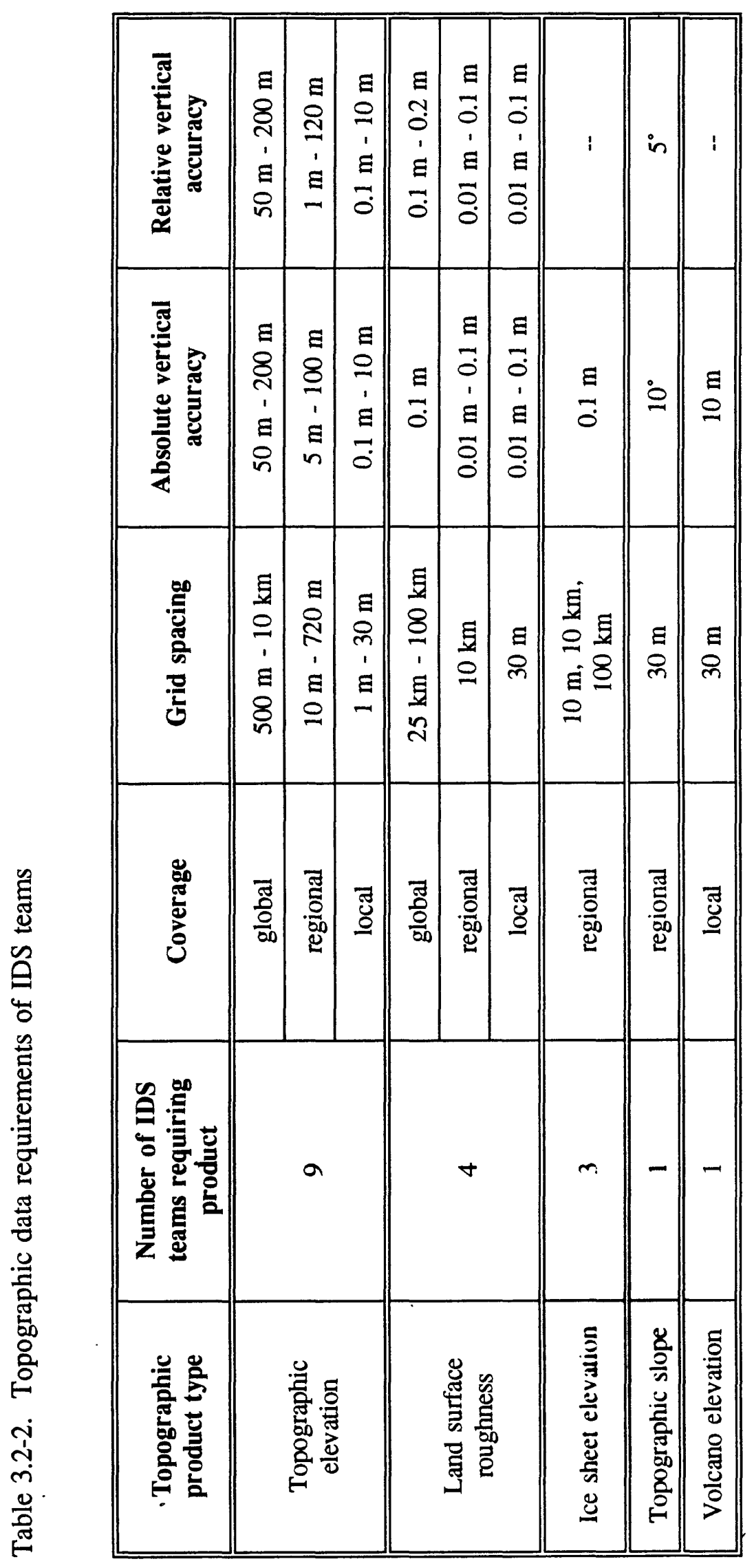


The IDS investigations address many of the earth system science priorities of the USGCRP that were first described in a 1990 report "Our Changing Planet: The FY 1991 Research Plan" (Committee on Earth Sciences, 1990). There are seven interdisciplinary science elements, and for each element there are several subtopics that more fully describe the required research. Table 3.2-3 lists the seven elements and the subtopics. The 1990 report also ordered the elements and subtopics by priority, and those priorities are depicted in table 3.2-3 as follows: the element with the highest priority is furthest left and priority decreases to the right; under each element the subtopics are listed in order of decreasing priority. The current and projected data set holdings of each DAAC were listed and described in the June 1993 report, "Science Data Plan for the EOS Data and Information System covering EOSDIS Version 0 and Beyond" (Schwaller, 1993). These data sets were mapped to the USGCRP science priorities to characterize the usefulness of Version 0 data sets for addressing the research objectives. Current and future DEM data holdings of the EDC Land Processes DAAC were identified as helping to meet the information requirements for many of the research areas. Topographic data are required for addressing 6 of 7 interdisciplinary science elements and 19 of 38 subtopics. Those elements and subtopics are identified in table 3.2-3.

\subsection{Effect of Data Unavailability}

Various levels of topographic information are required, ranging from coarse-resolution global data for atmospheric sensors to high-resolution data with meter- and centimeter-level vertical accuracies for local and regional areas. Because of the extensive use of topographic data in product generation and interdisciplinary science investigations, the lack of appropriate data at any stage will have a sequential effect as higher level products or model results are degraded.

Lack of consistent global coverage for any specific topographic data base is problematic because many of the EOS studies are global in nature. For example, requirements for topographic corrections of all pixel sizes of MODIS data would be met by using Digital Terrain Elevation Data (DTED). However, even if all DTED were accessible, only a part of the global land surface is covered. Product generation for the remaining part of the land surface would have to rely on different and probably less accurate data. Such a scenario would result in inconsistent product accuracy, and quantitative comparisons between different areas would become more difficult.

Several instrument teams and IDS teams require elevation data with a coarse grid spacing (approximately 10 kilometers) and a vertical accuracy of near 100 meters. Global elevation data with a 10-kilometer grid spacing does exist (ETOPO5 data base; see section 4.3), although the vertical accuracy is variable and is probably much worse than several hundred meters in some areas. Although such a data set has the required spatial coverage, the variable vertical accuracy would introduce errors of unknown magnitude in data products.

Another serious effect of topographic data unavailability is that most EOS data products depend on many types of input data, sometimes including data from other EOS instruments. Thus, the importance of a requirement for topographic data for the generation of a level 1 


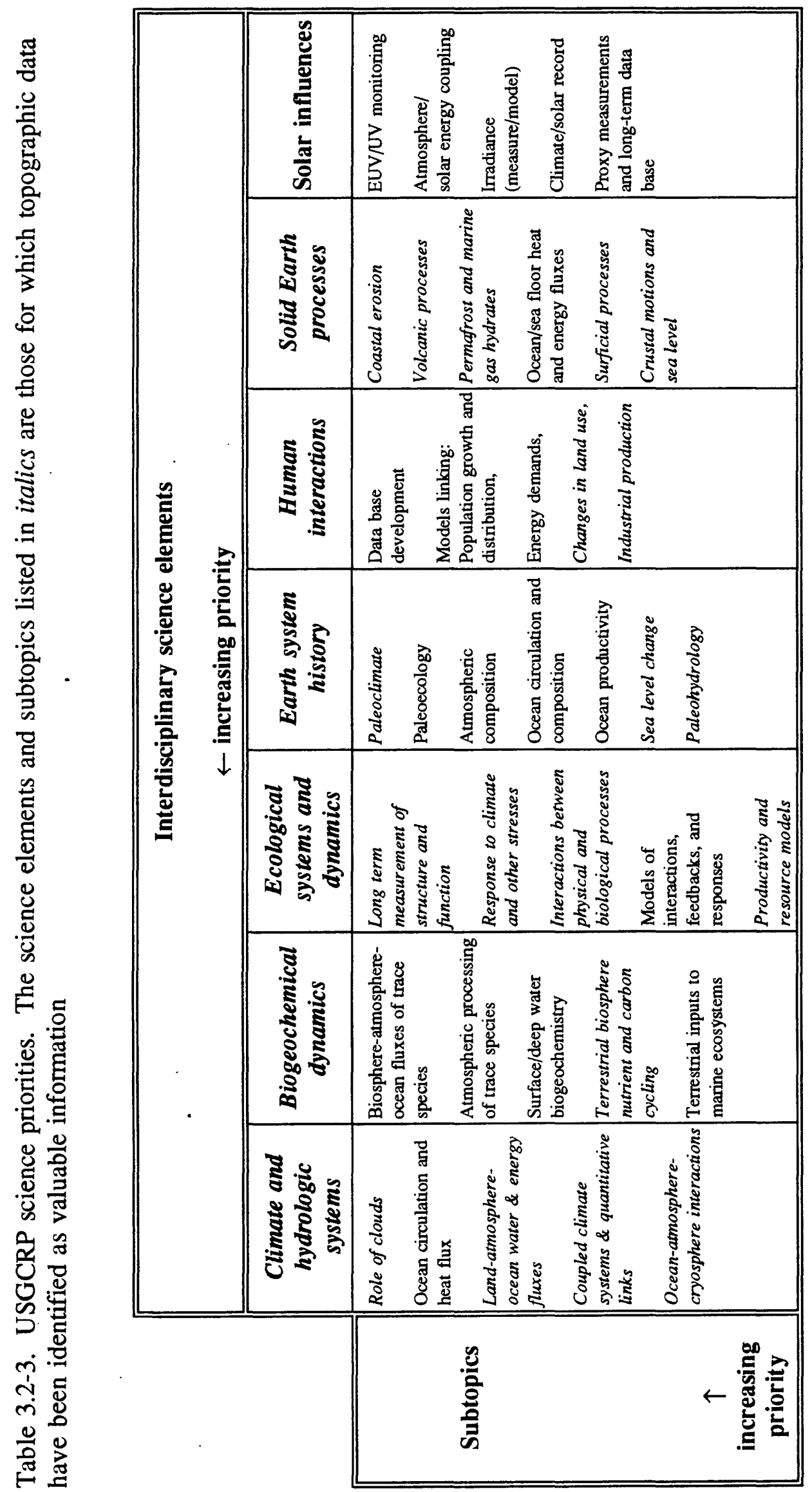


product is emphasized in the generation of all higher level products further down the product generation flow. For example, if MODIS level lB products are not geolocated accurately enough to allow for accurate terrain correction (orthoimage generation), all subsequent derived products will suffer from degraded spatial accuracy. This misregistration is especially serious for vegetation indices and other products that require multitemporal images as input. There are similar implications for ASTER level 1B data, which requires topographic information for the coregistration of data between and within telescopes. Any band misregistration error would be propagated through derived higher level products. Another example of dependency is found with the MISR land surface products, which require MODIS directional reflectance (which requires DEM as input data) for validation. Figure 3.3-1 shows the relationship among some MODIS, MISR, and ASTER products. The MODIS land cover products, which will be used widely in EOS investigations, depend on the accurate generation of several products incorporating terrain data.

The IDS investigations also depend on the availability of the instrument data products. Any degradation in the accuracy of the various data products because of inaccurate or unavailable topographic data will affect the usability of the products in physical process models. The SPSO, in its 1992 report, presented the results of an analysis to determine the best match between instrument team output products and IDS team input requirements. Table 3.3-1 shows the number of IDS teams that have requirements that can be met by certain types of instrument data products, all of which require topographic data to produce.

Table 3.3-1. Selected data products (produced with topographic data) required by IDS teams

\begin{tabular}{||c|c|c||}
\hline \multicolumn{1}{|c|}{ Instrument output product } & $\begin{array}{c}\text { Number of IDS teams requiring } \\
\text { product }\end{array}$ \\
\hline \hline \multirow{3}{*}{ MODIS } & Level 1B radiance & 4 \\
\cline { 2 - 3 } & Directional reflectance & 3 \\
\cline { 2 - 3 } & Bidirectional reflectance & 6 \\
\hline \hline \multirow{3}{*}{ ASTER } & Land cover type and change & 9 \\
\cline { 2 - 3 } & Surface roughness & 4 \\
\hline \hline MISR & Land surface emissivity & 2 \\
\hline
\end{tabular}




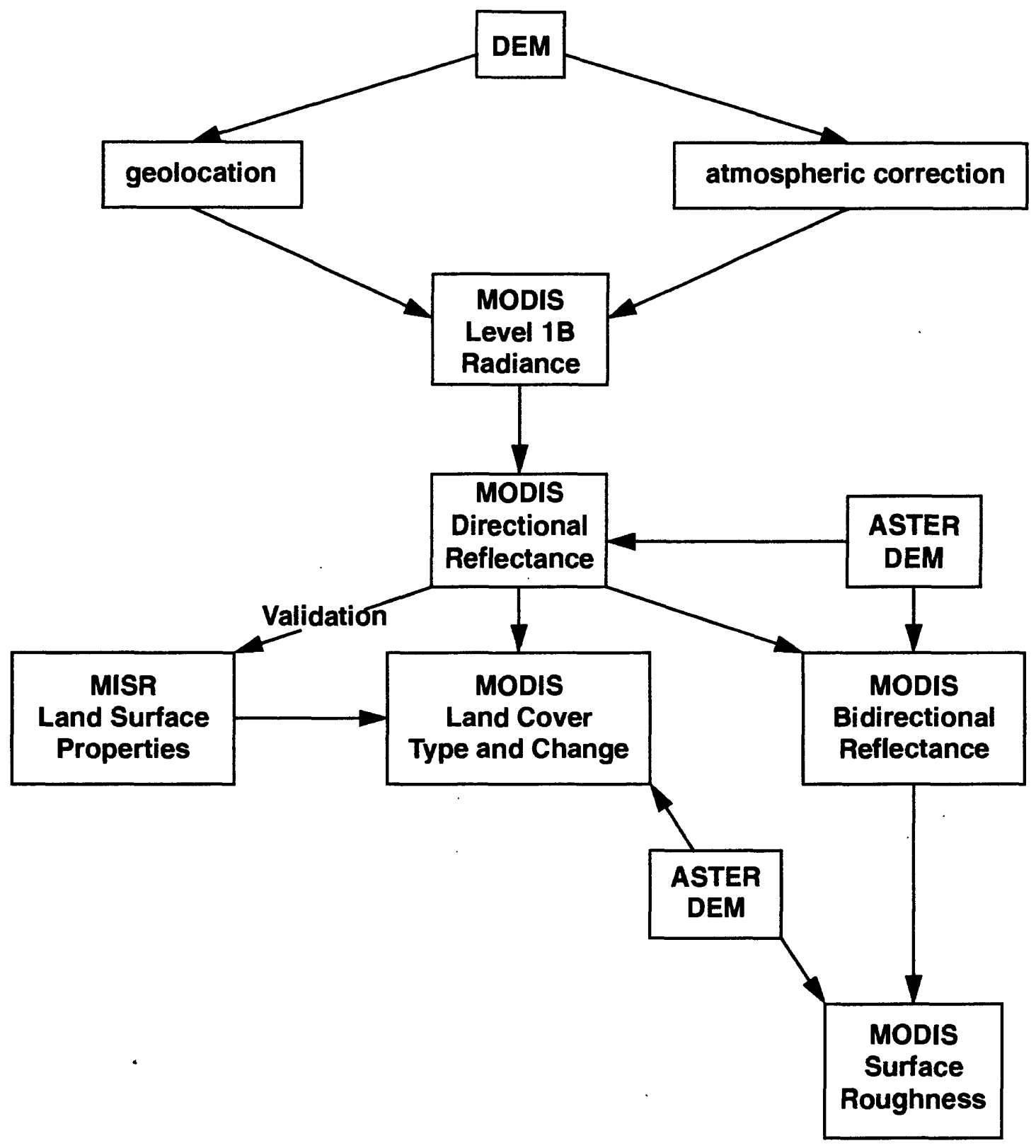

Figure 3.3-1. Algorithm dependency among some MODIS, ASTER, and MISR products 


\subsection{Status of Existing Topographic Data}

Even though a large amount of digital topographic data is available in the form of DEM's, coverage of the global land surface is inconsistent. Many different mapping organizations around the world produce and distribute elevation data, and the available data vary widely in scale, accuracy, distribution policy, copyright and royalty restrictions, and price. Wolf and Wingham (1992) reported on the status and availability of the world's digital elevation data. Their report describes the results of a survey of 352 mapping organizations from 64 countries. The report lists 50 different topographic data sets that vary widely in resolution and coverage. Data with a horizontal resolution of better than 500 meters are publicly available for only 10 percent of the global land surface.

\subsection{U.S. Geological Survey Data}

The U.S. Geological Survey (USGS) offers several levels of products for coverage of the United States. The country is completely covered by 3 arc second DEM's (approximately 90 meter horizontal resolution). Higher resolution DEM's with a 30-meter posting are available for about 50 percent of the continental United States. There is also partial coverage by 2 arc second DEM's, and by Digital Line Graph (DLG) hypsography data that are digitized contour lines from 1:100,000- and 1:24,000-scale cartographic sources.

Alaska is also mapped, but the elevation spacing intervals are different. Complete coverage is available at 3 by 6 arc seconds ( 3 by 9 arc seconds north of $70^{\circ}$ ). Parts of Alaska are also available at postings of 1 by 2 arc seconds and 2 by 3 arc seconds. All USGS DEM data are available through its network of Earth Science Information Centers. More specific information on USGS DEM's is given in appendix 8.2.

\subsection{Defense Mapping Agency Data}

The Defense Mapping Agency (DMA), has produced Digital Terrain Elevation Data (DTED) for much of the global land surface, with coverage concentrated in the northern hemisphere (Jenson and Larson, 1993). DTED production continues, with completion of a global data set anticipated in about 10 years. The DTED have an elevation spacing of 3 arc seconds (approximately 90 meters). For locations above $50^{\circ}$ north or south latitude, the longitude spacing between adjacent elevation posts increases. The published accuracy of DTED is 130meter horizontal and \pm 30 -meter vertical (Defense Mapping Agency, 1986). A full description of DTED level 1 characteristics is found in appendix 8.3.

The DTED data base could serve as a valuable source of topographic information for global change science, but access to data for areas outside the United States is limited to agencies within the executive branch of the U.S. Government. Restrictions also are placed on the publication of derived products and research results. Distribution of the data is also limited by international agreements imposed by foreign governments who have cooperated with DMA on DTED production (Space News, 1993). Acting as an advocate for the science community, 
the USGS has begun a series of discussions with DMA aimed at facilitating the release and distribution of DTED, or generalizations of DTED, to civilian scientific users.

The DTED for parts of Canada and Mexico are available from the mapping organizations in those countries. Canadian DTED are sold by Energy, Mines and Resources Canada, and Mexican DTED are offered by the Mexican National Institute for Statistics, Geography, and Information (INEGI). Although organizational agreements and distribution procedures are not yet completed, Mexican DTED will be available to noncommercial users through the EDC. The DTED have become available as part of a data exchange with INEGI, which is receiving multitemporal Landsat MSS coverage of Mexico as part of the North American Landscape Characterization (NALC) Pathfinder project, an Environmental Protection Agency (EPA) project in which the EDC is participating. The EDC plans to generate and distribute a generalized DTED product for Mexico.

\subsection{Other Data}

ETOPO5 are the highest resolution topographic data with global coverage that are publicly available. The ETOPO5 data set has elevations posted every 5 arc minutes (approximately 10 kilometers) for all land and sea floor surfaces. These data are distributed without restriction by the National Oceanic and Atmospheric Administration (NOAA) through its National Geophysical Data Center (NGDC). NGDC also offers global coverage with 10 arc minute data. NGDC is updating ETOPO5 with some improved source data for certain areas, and the planned release date for the new version is late 1994.

Wolf and Wingham's 1992 report includes a catalog of the world's publicly available topographic data, both raster elevation models and digitized contours. Besides the data sets already mentioned, DEM's exist for most of Western Europe, Australia, South Africa, and Japan. Parts of Antarctica, Canada, Australia, and New Zealand are covered by digital hypsographic data. 


\subsection{Alternatives for Topographic Data Generation}

It is clear that existing data do not adequately fulfill the global requirements imposed by EOS. Various sources for generating new topographic data exist or are being developed. Consequently, the utility of each of these sources for helping to meet the EOS requirements by the launch of the AM1 platform in 1998 varies. Data are also needed before the launch for processing existing sensor data and for developing and validating product generation algorithms. All the sources described below can contribute to meeting needs during the EOS era.

\subsection{Cartographic Sources}

\subsubsection{Digital Chart of the World}

DMA produced the Digital Chart of the World (DCW), a vector data base, by digitizing the 270 maps in the 1:1,000,000-scale Operational Navigation Chart (ONC) series, which represents the largest scale base map source having global coverage (Danko, 1992). The Antarctic part of the DCW was derived from the 1:2,000,000-scale Jet Navigation Chart (JNC) series so that all land areas would be covered. The DCW contains all the information from the source maps, and the cartographic, attribute, and text data portray political boundaries, drainage features, topography, utility and transportation networks, urban areas, and land cover.

The topographic information in the DCW is contained in several hypsography layers. The primary contour interval on the ONC's is 1,000 feet, and supplemental contours with an interval of 250 feet are found in areas below 1,000 feet in elevation. Spot heights on the source maps have also been digitized into the DCW data base. Elevations of some larger inland water bodies are also included.

Staff at the EDC have investigated the use of DCW hypsographic and drainage data for the generation of gridded (raster) elevation models (Jenson and Larson, 1993). The feasibility of such processing was established over several test sites, and the resulting DCW grids have compared favorably with generalized higher resolution data sets. Raster data are being produced at a grid spacing of 30 arc seconds (approximately 1 kilometer). The surface interpolation routine incorporates drainage information to perform "drainage enforcement," which results in an elevation model of higher quality and accuracy (Hutchinson, 1989). Production processing has begun on the DCW data for Africa and portions of North America, with the goal of eventual global coverage. Although many applications require topographic data with a resolution greater than 1 kilometer, this data set will be useful for many studies, especially those that require global or regional coverage at resolutions higher than that currently provided by ETOPO5. This data set will also be an important contribution to the proposed GLOBE project (Schreier and Muller, 1992), which includes a recommendation for a global 1-kilometer elevation data base. More information on grids derived from the DCW is found in appendix 8.4. 


\subsubsection{Vector Smart Map}

DMA is developing a product similar to the DCW, known as Vector Smart Map (VMAP), in which the information in the data layers is equivalent to the detail found on a 1:250,000-scale map. Canadian and British military mapping organizations are cooperating with DMA on VMAP production. Several prototypes have been produced, and they are being evaluated by users as prototype production continues. Prototypes are based on information digitized from existing 1:250,000-scale Joint Operations Graphics (JOG). The projected completion time for global coverage is within 7 years. Some areas will also be covered at larger scales, such as 1:50,000. Global coverage of digital hypsographic data at 1:250,000 scale would be an invaluable resource for generating raster elevation models. Because the product is still in the prototype stage, it is not known what type of distribution restrictions will apply, although it is likely that it will not be as freely distributed as the DCW.

\subsubsection{Other Cartographic Sources}

Digital hypsographic data of variable scale exist for selected areas of the globe. For example, Canada has digital vector topographic data derived from 1:250,000-scale sources available for the entire country (Energy, Mines and Resources Canada, 1990). Energy, Mines and Resources Canada also distributes 1:50,000-scale data for selected areas, and countrywide coverage is projected to be completed by 2000 .

Although raster elevation models exist for the United States, digital hypsographic data are also available for some areas. Digital Line Graph (DLG) data include hypsography at $1: 24,000$ and 1:100,000 scales, and some of these data were used as the source for the raster DEM's.

Parts of Australia and New Zealand are also covered by digitized contours. As is the case with all digital hypsographic data, they are most useful after vector-to-grid conversion has been completed. Gridding of vector hypsography can be computationally demanding and very time consuming, because in many cases the vector data need significant editing. There is also a wide choice of algorithms for surface interpolation, and the quality of the output from them varies considerably. For these reasons, it is usually much more convenient for scientists to receive gridded elevation models than to create them.

Digital vector data can be created from hardcopy sources for those areas that are covered by topographic maps. Usually maps or contour separates are raster scanned and then automatic vectorization (line following) is performed. The next step is to edit the vector contours and tag them with the correct elevation value. Depending on the quality of the hardcopy source and the raster scan and the capabilities of the editing software, the process can range from being very simple to being extremely complicated and time consuming. After vectorization and editing are completed, the surface generation routine is run to create the raster elevation model. 
Processing digital hypsographic data to create raster DEM's may be important for meeting some specific EOS requirements. Although it is not possible to create global DEM coverage in this manner, data for specific regions or local sites can be generated. These raster DEM's will be useful for filling gaps in existing data bases, such as the DTED and the DCW.

\subsection{Remote Sensing Sources}

\subsubsection{Optical Stereo}

Optical stereo images are the most common remote sensing source used to generate topographic data. Stereo aerial photographs have been the most widely used source for producing of topographic maps for many years. Mapping photographs, acquired with specialized aerial camera systems, and ground survey control points are used in stereoplotters in photogrammetric production systems to produce analog and digital topographic information. The elevation data produced in this manner are usually very accurate, highresolution data that are often used to produce large-scale (greater than 1:100,000) topographic maps. Stereo aerial photographs remain an important source for generating local coverage of detailed topographic data.

Digital stereo satellite images are another important source of topographic information. When stereo SPOT images became available in 1986, the possibility of generating topographic data from satellite images on a routine basis became a reality. Although the SPOT sensors are not a true mapping system (they do not acquire "simultaneous" stereo images), the availability of stereo satellite data spurred significant advances in image processing techniques aimed at automating the extraction of elevation data. Numerous research and academic institutions have produced DEM's from SPOT images, and several commercial organizations offer DEM generation from SPOT images as a service.

The Japanese Earth Resources Satellite (JERS-1) also carries an optical stereo sensor. Unlike SPOT, JERS-1 does collect simultaneous stereo images in the along-track direction. Large amounts of JERS-1 stereo data are not yet available, but using the data as a source for DEM's has been demonstrated (Shimada, 1992).

Several satellite stereo imagers are planned for launch later this decade. AVNIR (Advanced Visible and Near-Infrared Radiometer) is a sensor designed for the Japanese Advanced Earth Observing System (ADEOS) platform scheduled for launch in 1996. ASTER and MISR on the EOS-AM1 platform will collect simultaneous stereo images suitable for DEM generation. SPOT 5, planned for launch in 2000 , will employ fore and aft pointing sensors to collect 5meter panchromatic stereo images. The High Resolution Multispectral Stereo Imager (HRMSI), capable of collecting 5-meter stereo images, had been planned originally for Landsat 7 but now has been deleted from the most recent Landsat 7 payload configuration. More details on existing and planned stereo optical systems are provided in appendix 8.5. 
Several problems are common to all stereo-optical systems. The foremost is cloud cover. Valid topographic data cannot be extracted for terrain covered by clouds on the images. This points out one of the advantages of simultaneous stereo acquisition in contrast to repeat-pass systems, such as SPOT, that require multiple cloud-free acquisitions to obtain usable stereo data. However there are some areas, namely the tropics, that are rarely cloud free, and even with simultaneous acquisition the chances of obtaining completely cloud-free images on any pass remain low. Digital image matching is a common processing technique for stereooptical images, and several limitations of the data affect results. Corresponding surface features represented in the images need sufficient contrast so that they can be reliably matched. Also, in forested areas, the height derived from matching stereo-optical images usually represents the top of the canopy, and thus a bias equal to the vegetation height is introduced into the elevation model. This limitation of measuring heights at the top of the canopy is also present in other remote sensing systems.

With the increased availability of digital stereo images, the disciplines of photogrammetry and image processing have become more closely aligned. Softcopy photogrammetry incorporates the principles of precise measurement from traditional photogrammetry performed on hardcopy aerial images with the information extraction techniques of digital image processing. Digital images, either from electro-optical satellite sensors or conventional frame photographs that have been digitized, are used to derive very detailed topographic information. This merging of technologies is evidenced by the increasing number of commercially available image processing systems that include stereo data extraction tools. The prerequisite for generating very accurate elevation data with these tools is precise knowledge of the position and attitude of the sensor during the imaging event. Fortunately, the modeling of airborne and spaceborne platforms has advanced enough so that the required location knowledge can be calculated. This requirement is true not only for stereo optical-sources but for all other remote sensing sources as well. The next major advance will occur when the geolocation information provided with an image is accurate enough that post-acquisition modeling of the viewing geometry based on ancillary control will not be required.

Stereo-optical images will remain an important source for providing the topographic data required by EOS. Processing techniques are operational and relatively mature, and new sensors will increase the availability of suitable images.

\subsubsection{Synthetic Aperture Radar Interferometry}

Synthetic aperture radar (SAR) interferometry is a technique that uses two SAR antennas with a known baseline separation to collect stereo radar images. The difference in phase between the radar returns is measured for each pixel. This phase difference is proportional to the difference in path length from each antenna to the surface and is thus influenced by elevation. A phase-difference "image" is generated by registering the two SAR images and then performing cross correlation. Contours in the phase-difference image correspond to contours of topographic height. Incorporating platform position and attitude information and (or) control points allows the phase differences to be converted to terrain heights to create a DEM. 
The development of SAR interferometric techniques is an active research area. ERS-1 (European Remote Sensing Satellite) SAR data have been used to generate highly accurate DEM's (Prati, Rocca, and Monti Guarnieri, 1992; Coulson, 1992). The ERS-1 SAR data used for interferometric processing are acquired in multiple passes, and variation in the ERS-1 orbit affects the usability of the images. The proper baseline and coherence between the images must be present. Changes in the scattering properties of a target between image acquisitions result in degraded coherence, which affects correlation, so measured phase difference becomes a less reliable source of terrain height information. To date, there has not been a dedicated spaceborne SAR interferometry mission. The SAR data used in experiments, mostly ERS-1 and Seasat data, were acquired in multiple passes with an adequate baseline and date separation that allowed successful processing.

Several options exist or are in the planning stages for acquiring SAR data with the proper characteristics for interferometric applications. JPL acquires interferometric SAR data with an airborne sensor (TOPSAR) that uses dual C-band antennas. TOPSAR has gathered data for the further development of interferometric techniques and applications (Evans, Farr, Zebker, van Zyl, and Mouginis-Mark, 1992). A satellite mission carrying an interferometric SAR system has been proposed, and NASA has established a working group to analyze mission options, although no funding for such a mission has been appropriated. Several possible configurations have been presented for the Global Topography Mission (GTM) (Farr and others, 1994), also known informally as TOPSAT. One configuration includes dual spacecraft orbiting at a controlled separation distance to maintain the required baseline. Each satellite would carry an L-band radar. An alternative configuration calls for two Ka-band radar antennas on one platform. The predicted accuracy of elevation measurements from both configurations is better than 6 meters. A laser altimeter is also proposed for GTM to provide very accurate mapping of the Earth's ice sheets.

SAR interferometry has significant potential for providing very accurate topographic data. Experiments with ERS-1 data have shown that elevation data with a vertical accuracy of 5 meters can be produced, and further advances should allow production of data with an accuracy of better than 2 meters. Another major advantage of the technique is that cloud cover and illumination conditions do not affect data acquisition. It has been estimated that the proposed GTM could acquire global coverage of interferometric SAR data in 6 months.

\subsubsection{Radar Altimetry}

Radar altimeters can acquire data day and night, and the data are not degraded by cloud cover as happens with optical techniques. Topographic data of moderate to low horizontal resolution and high vertical accuracy (1 to 3 meters) can be collected. Seasat radar altimeter data have been successfully gridded for continental areas (Frey and Brenner, 1990; Devayya. Wingham, Palmer, Birkett, and Ridley, 1992). Although the resulting grids have coarse horizontal resolution, on the order of 100 kilometers, the high vertical accuracy allows the data to be used to check the quality of other topographic data sets, such as ETOPO5 and gridded DCW elevation data. ERS-1 also carries a radar altimeter that provides topographic 
information. One limitation of radar altimetry is that data collected over high-relief terrain are suspect because it is difficult to separate the off-nadir echo from the nadir return. As such, the usefulness of radar altimetry data are limited to relatively flat terrain unless slope corrections are incorporated. A design for a scanning SAR altimeter has been proposed, and this configuration would remove limitations of data acquired over rugged terrain (Topographic Science Working Group, 1988).

\subsubsection{Laser Altimetry}

Laser altimetry is a useful technique for obtaining elevation data with centimeter-level vertical accuracy. Such data are required for mapping continental ice sheets. Monitoring dynamic landforms, such as landslide areas and active volcanos, also requires high-resolution data. Airborne laser altimeters have been used to gather high-quality data over local areas, but no operational spaceborne laser altimeter currently exists.

Recent advances in processing airborne laser altimetry data show promise for overcoming a disadvantage common to methods of remote sensing of topography, that of measuring height at the top of the vegetation canopy instead of at the underlying ground surface. Analysis of the waveforms of backscattered laser altimeter pulses has demonstrated measurement of the ground surface beneath the canopy with accuracy better than 1 meter (Blair, Harding, and Bufton, 1993).

The laser altimeter proposed for the GTM, the Multi-Beam Laser Altimeter (MBLA), would collect data with a vertical accuracy ranging from 20 centimeters in zero slope areas to 3 meters in $20^{\circ}$ slope areas. The MBLA includes five laser emitters for collecting five adjacent 30 -meter pixels, resulting in a narrow swath of 150 meters directly below the spacecraft. In addition to measuring polar ice sheet elevations, the MBLA will be used to control and calibrate the GTM interferometric SAR data and to measure vegetation height and surface roughness.

The Geoscience Laser Altimeter System (GLAS) is an EOS instrument scheduled for launch in 2002. GLAS will collect data with a laser footprint of 70 meters and a vertical precision of 10 centimeters. The limitations of laser altimetry are an inability to penetrate cloud cover, significant power requirements on board the spacecraft, and a limited swath width that would require an unrealistically long mission to obtain global coverage.

Table 5-1 represents a summary of information compiled by the Terrain Mapping Subgroup of the CEOS Working Group on Calibration/Validation (CEOS, 1992). The table shows a comparison of different methods for measuring terrain heights by satellite remote sensing. The differential SAR interferometry, SAR stereo, and monopulse radar methods are either very recent developments or are limited by a lack of data coverage and, as such, are currently less relevant for meeting EOS topographic data requirements. 


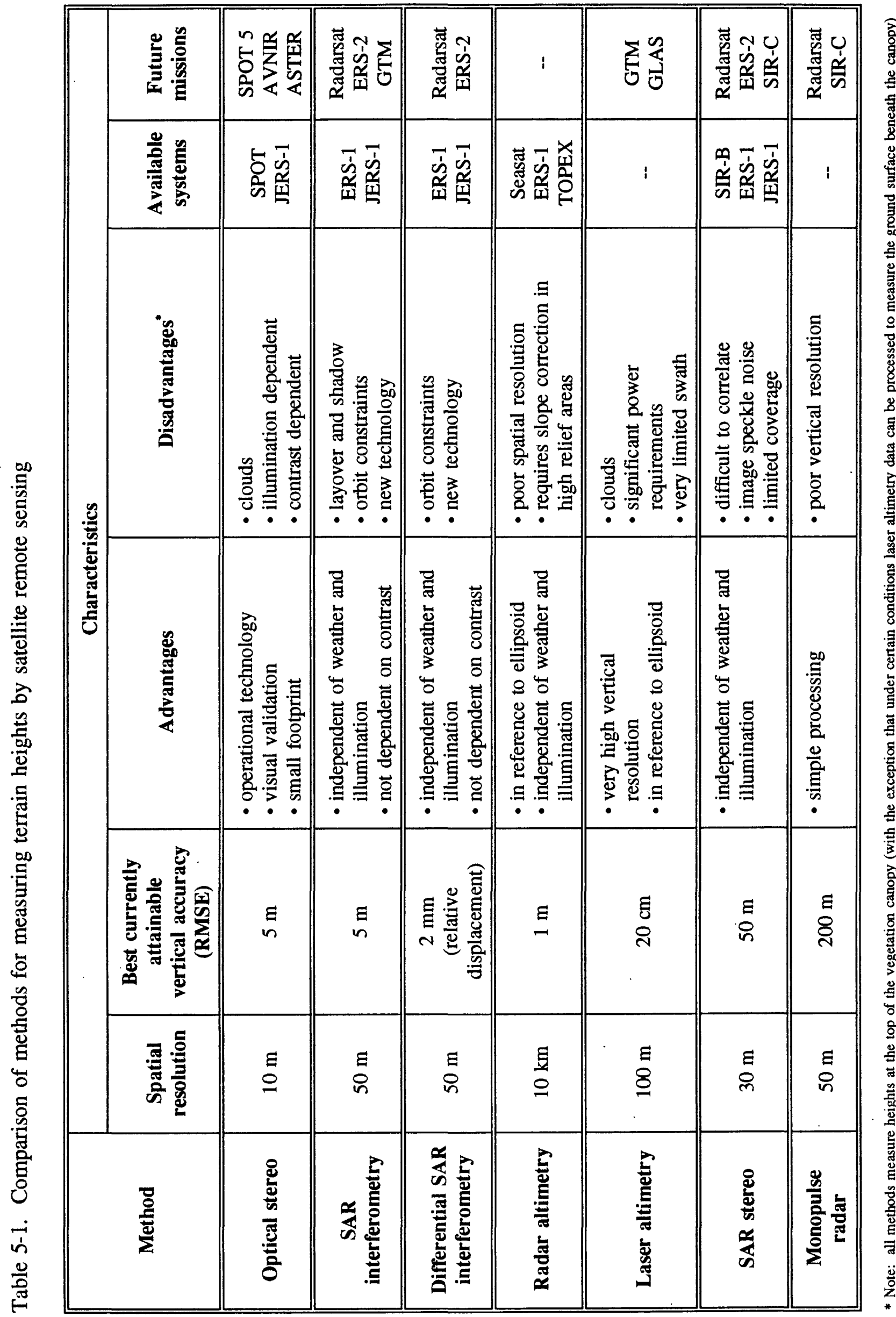


Table 5-2 presents a summary of current and future sources of digital topographic data. Grid spacing pertains to existing raster elevation data and pixel size refers to the spatial resolution of image sources that can be processed to derive elevation information. Status indicates if the source currently exists or the year in which it will become available. More detailed information on many of these sources is provided in appendixes 8.2 through 8.5 .

Table 5-2. Current and future sources of digital topographic data

\begin{tabular}{|c|c|c|c||}
\hline Source & Status & $\begin{array}{c}\text { Grid spacing } \\
\text { or pixel size }\end{array}$ & Coverage \\
\hline \hline ETOPO5 & exists & $5^{\prime}(10 \mathrm{~km})$ & global \\
\hline DCW grid & exists & $30^{\prime \prime}(1 \mathrm{~km})$ & $\begin{array}{c}\text { Africa, North } \\
\text { America }\end{array}$ \\
\hline DTED & exists & $3^{\prime \prime}(90 \mathrm{~m})$ & $\begin{array}{c}\text { predominantly } \\
\text { Northern Hemisphere }\end{array}$ \\
\hline $7.5^{\prime}$ DEM & exists & $30 \mathrm{~m}$ & $50 \%$ U.S. \\
\hline SPOT & exists & $10 \mathrm{~m}$ & regional \\
\hline JERS-1 & exists & $18 \times 24 \mathrm{~m}$ & local \\
\hline ERS-1 & exists & $50 \mathrm{~m}$ & local \\
\hline TOPSAR & exists & $10 \mathrm{~m}$ & local \\
\hline \hline AVNIR & 1996 & $8 \mathrm{~m}$ & regional \\
\hline ASTER & 1998 & $15 \mathrm{~m}$ & regional \\
\hline MISR & 1998 & $500 \mathrm{~m}$ & global potential \\
\hline $\begin{array}{c}\text { TOPSAT (GTM) } \\
\text { SAR }\end{array}$ & 1999 & $30 \mathrm{~m}$ & global \\
\hline $\begin{array}{c}\text { TOPSAT (GTM) } \\
\text { laser }\end{array}$ & 1999 & $30 \mathrm{~m}$ & predominantly polar \\
\hline GLAS & 2002 & $70 \mathrm{~m}$ & polar regions \\
\hline \hline
\end{tabular}




\subsection{Summary and Recommendations}

The topographic data requirements imposed by EOS instrument teams and IDS investigations vary widely. Some requirements are met by existing data, but there are definite data shortages for numerous areas and applications. Ideally, the solution is a high-resolution, highly accurate DEM data base with complete coverage of the entire global land surface. A data set with grid spacing of at least 30 meters and an absolute vertical accuracy of 5 to 10 meters would fulfill all but a few requirements. A data base with 100 -meter grid spacing and an absolute vertical accuracy of 30 meters, which is technically feasible with current technology, would fulfill many requirements, including all geometric correction and geolocation requirements for MODIS and MISR data. Some radiometric correction requirements, especially those of higher resolution ASTER data, would not be met by such a data set.

A data base with the required detailed, accurate, and consistent global coverage does not exist, and it is unlikely that it will exist before the EOS-AM1 launch in 1998. Therefore, existing data must be utilized to the maximum extent possible, and future sources of topographic data must be carefully evaluated to determine their usefulness for providing data that match the known requirements as closely as possible. Further study is required on several aspects of the topographic data requirements of EOS, and one of the most important is algorithm dependency. Such analysis will produce the best understanding of the impact on science if specific data requirements are not met in the proper timeframe.

\subsection{Requirements versus Existing Data}

Existing topographic data do fulfill some EOS requirements, although none of the usable data bases has complete global coverage. The 1-kilometer gridded elevation data set derived from the DCW will be adequate for first-order atmospheric corrections (those that adjust for gross changes in atmospheric path length), and it will also be useful for geometric correction processing of MODIS 1,000-meter data. Generalized DCW grids will be useful for the level of topographic information required for CERES, AIRS, and EOSP product generation. The ETOPO5 10-kilometer data set may even be useful if the vertical accuracy can be properly characterized.

DTED has the resolution and accuracy to meet the requirements for geolocation, geometric correction, and most radiometric processing of MODIS data (see table 3.1.1-2) and MISR data. Generalized DTED would be more than adequate for coregistration of ASTER SWIR bands, and the DCW grids may even be adequate. The DTED data base, covering a majority of the global land surface, is the closest thing to the globally consistent elevation data set that is required.

DTED and DCW grids will fulfill many IDS requirements. Generalized DTED would be useful for applications requiring grid spacing between 100 meters (full-resolution DTED) and 1,000 meters (DCW grid). Some of the IDS and instrument team requirements for high- 
resolution local data, such as test and validation sites, can be met by DEM's derived from SPOT data, JERS-1 data, aerial photographs, and USGS 30-meter DEM's.

\subsection{Requirements versus Future Sources}

Some EOS requirements will be met by planned sources of topographic information, sources that will be available after launch of the first EOS platform. High-resolution data are required to determine subpixel illumination conditions for the radiometric correction of MODIS, MISR, and ASTER data. Such data will be available from processing ASTER images and possibly SAR interferometry data.

DEM's derived from MISR data will be a good source of elevation information for those applications requiring more generalized knowledge of the topography, such as first-order atmospheric correction and regional slope measurements. MISR DEM's may be valuable for filling gaps in DTED and DCW grid coverage.

If the entire DTED data base is released and DCW grids are completed for all areas where DCW hypsography is available, processing new sources, both remote sensing and cartographic, should be concentrated on the areas of the globe not covered by those data sets. ASTER and MISR data will be helpful in this regard, although reliance on them as DEM sources for "at launch" products is problematic.

\subsection{Topics Requiring Further Study}

The process of documenting EOS topographic data requirements has pointed out several topics that require further analysis. For all applications (product generation and process modeling), the requirements need to be more fully characterized. The values for grid spacing, horizontal accuracy, vertical accuracy, and vertical precision (relative accuracy within a given data set) must be specified in all cases. Likewise, for all existing and proposed topographic data sets, all data characteristics must be fully described, including horizontal accuracy, absolute vertical accuracy, vertical precision (relative accuracy), and slope resolution. If all characteristics are fully quantified for requirements and sources, then a more valid match can be determined. The instrument teams that are defining and generating data products and the IDS teams that use topographic data as model input are responsible for fully specifying their requirements, and the producers of topographic data are likewise responsible for thorough and complete accuracy statements accompanying their data.

The accuracy of existing, more general elevation data, such as ETOPO5 and DCW grids, could be analyzed by comparison with radar altimetry data, which have coarse spatial resolution but very high vertical accuracy, especially in low slope areas. Artifacts in other elevation data bases, especially DMA DTED and USGS DEM's, should be analyzed to determine their effect on sensor data processing and physical process model calculations.

The data requirements for radiometric processing, such as slope resolution, need to be better 
defined. These requirements are less well understood than geometric processing requirements, but the radiometric requirements are generally more stringent.

Algorithm dependency among EOS data products must be more fully investigated. When all the interactions among instrument products and IDS models are known, then the impact of data unavailability on global change science can be better determined. Admittedly, these relationships will evolve as the EOS program progresses, especially after launch, but they must be analyzed at regular intervals so that changing topographic data requirements will be identified at the earliest possible point.

Some IDS teams and instrument teams have indicated a need for high-resolution data at local sites. These teams should specify the exact location of these sites so that the generation of DEM's from existing sources can be completed. In this manner, the utility of these existing high-resolution sources (and similar planned sources) can be determined. Also, the requirements for the mapping of ice sheets should be clearly defined to determine if any alternate sources for near-term studies are available. This is important, because the EOS sensor that will be useful for mapping polar regions, GLAS, will not be launched until 2002.

The feasibility, including costs and benefits, of acquiring and processing all publicly available existing non-U.S. DEM's, digital hypsographic data, and hardcopy topographic maps should be fully investigated. Such a collection of topographic information would include a variety of scales and accuracies, and any resulting DEM would certainly be a "hybrid" product, but in the absence of a definite dedicated mapping mission, such a data set could provide useful information in areas where the need is critical.

The proposed GTM should be objectively evaluated by the EOSDIS user community to determine the extent to which the proposed data products, collection strategy, and schedule help meet EOS topographic data requirements. Such an objective evaluation by a potentially large GTM data user community would be valuable as NASA determines the direction and future of a dedicated topographic mission.

In late 1994 or early 1995, ERS-2 will be launched. A proposal was endorsed by the SAR interferometry community to dedicate the operation of ERS-2 in tandem with ERS-1 to acquire global coverage of interferometric SAR data suitable for producing high-resolution DEM's. Such an effort would require significant international collaboration for data acquisition and production processing, but this approach should be investigated in depth.

In general, international collaboration for addressing the critical need for better global topographic data should be vigorously pursued. A project or organization with strong international scientific support, such as IGBP or CEOS, is a logical choice for leading such an effort. 


\subsection{References}

Acevedo, W., Mathiasmeir, T., and Norvelle, F.R., in press, Assessment of digital elevation models produced by digital correlation techniques: Photogrammetric Engineering and Remote Sensing.

Asrar, G., and Dokken, D.J., eds., 1993, EOS reference handbook: NASA, Washington, D.C., $145 \mathrm{p}$.

Blair, J.B., Harding, D.J., and Bufton, J.L., 1993, Measurement of ground topography and vegetation height by laser altimetry: Eos, Transactions, American Geophysical Union, v. 74 , no. 16 , p. $194-195$.

Committee on Earth Sciences, 1990, Our changing planet: the FY 1991 research plan: Federal Coordinating Council for Science, Engineering, and Technology, Office of Science and Technology Policy, Washington, D.C.

Committee on Earth and Environmental Sciences (CEES), 1992, The U.S. global change data and information management program plan: Federal Coordinating Council for Science, Engineering, and Technology, Office of Science and Technology Policy, Washington, D.C., 94 p.

Committee on Earth Observation Satellites (CEOS), 1992, Proceedings of the terrain mapping subgroup, working group on calibration/validation: Jet Propulsion Laboratory, Pasadena, Calif.

Committee on Opportunities in the Hydrologic Sciences, Water Science and Technology Board, Commission on Geosciences, Environment, and Resources, National Research Council, 1991, Opportunities in the hydrologic sciences: National Academy Press, Washington, D.C., 348 p.

Coulson, S.N., 1992, SAR interferometry with ERS-1, in Earth Observation Quarterly, no. 40: ESA Publications Division, Noordwijk, The Netherlands.

Danko, D.M., 1.992, The digital chart of the world: GeoInfo Systems, v. 2, no. 1, p. 29-36.

Defense Mapping Agency, 1986, Defense Mapping Agency product specifications for digital terrain elevation data (DTED) (2d ed.): Defense Mapping Agency Aerospace Center, St. Louis, Mo., 26 p.

1990, Digitizing the future (3d ed.): Defense Mapping Agency, Washington, D.C., 105 p. 
Devayya, R.H., Wingham, D.J., Palmer, D.E., Birkett, C.M., and Ridley, J.G., 1992, The error spectrum of the ETOPO5 global elevation model: Proceedings of the Terrain Mapping Subgroup, Working Group on Calibration/ Validation, Committee on Earth Observation Satellites, Jet Propulsion Laboratory, Pasadena, Calif.

Diner, D.J., ed., 1993, Report of the image navigation working group to the science working group of the AM Project: Jet Propulsion Laboratory, Pasadena, Calif, $21 \mathrm{p}$.

Energy, Mines and Resources Canada, 1990, National Atlas Information Service: Geographical Services Division, Canada Centre for Mapping, Ottawa, Ontario.

Evans, D.L., Farr, T.G., Zebker, H.A., van Zyl, J.J., and Mouginis-Mark, P.J., 1992, Radar interferometry studies of the Earth's topography: Eos, Transactions, American Geophysical Union, v. 73, no. 52, p. 553-558.

Farr, T., Evans, D., Zebker, H., Harding, D., Bufton, J., Dixon, T., Vetrella, S., and Gesch, D., in press, The global topography mission: Eos, Transactions, American Geophysical Union.

Frey, H., and Brenner, A., 1990, Australian topography from Seasat overland altimetry: Geophysical Research Letters, v. 17, p. 1533-1536.

Guindon, B., in press, Aspects of digital elevation data requirements for operational geocoding of RADARSAT imagery: Canadian Journal of Remote Sensing.

Harding, D.J., 1992, Global topography requirements and capabilities: NASA Goddard Space Flight Center, Greenbelt, Md, 4 p.

Hubanks, P.A., and Fleig, A.J., 1993, An analysis of MODIS Earth location error - version 1.0: NASA Goddard Space Flight Center, Greenbelt, Md, 32 p.

Hutchinson, M.F., 1989, A new procedure for gridding elevation and stream line data with automatic removal of spurious pits: Journal of Hydrology, v. 106, p. 211-232.

International Geosphere-Biosphere Program (IGBP), 1992, Improved global data for land applications - IGBP report no. 20: IGBP Secretariat, Stockholm, Sweden, 87 p.

Isacks, B.L., and Mouginis-Mark, P., 1992, Solid Earth panel report, in The Earth Observer, v. 4, no. 1: EOS Project Science Office, NASA Goddard Space Flight Center, Greenbelt, Md.

Jenson, S.K., 1991, Applications of hydrologic information automatically extracted from digital elevation models: Hydrological Processes, v. 5, p. 31-44. 
Jenson, S.K., and Domingue, J.O., 1988, Extracting topographic structure from digital elevation data for geographic information system analysis: Photogrammetric Engineering and Remote Sensing, v. 54, p. 1,593-1,600.

Jenson, S., and Larson, K., 1993, Availability of digital topographic data, in United States Geological Survey Yearbook Fiscal Year 1992: U.S. Government Printing Office.

Moore, B., and Dozier, J., eds., 1992, Adapting the Earth Observing System to the projected $\$ 8$ billion budget - recommendations from the EOS investigators, $48 \mathrm{p}$.

Morrison, A., 1993, U.S. ASTER science team, in The Earth Observer, v. 5, no. 4: EOS Project Science Office, NASA Goddard Space Flight Center, Greenbelt, Md.

Muller, J.P., 1993, Topography requirements for MODIS: University College London, 5 p.

Muller, J.P., Day, T., Upton, M., and Booth, P., 1992, Benchmarking terrain mapping techniques: lessons from the SPOT stereo experience: Proceedings of the Terrain Mapping Subgroup, Working Group on Calibration/ Validation, Committee on Earth Observation Satellites, Jet Propulsion Laboratory, Pasadena, Calif.

Muller, J.P. and Eales, P., 1990, Global topography accuracy requirements for EOS: Proceedings of IGARSS '90, Washington, D.C., p. 1,411-1,414.

National Geophysical Data Center, 1988, Topography data base - data announcement 88-SE1102: National Geophysical Data Center, Boulder, Colo.

Prati, C., Rocca, F., and Monti Guarnieri, A., 1992, SAR interferometry with ERS-1 elevation errors in the Bonn experiment: Proceedings of the Terrain Mapping Subgroup, Working Group on Calibration/ Validation, Committee on Earth Observation Satellites, Jet Propulsion Laboratory, Pasadena, Calif.

Running, S.W., in press, Terrestrial remote sensing science and algorithms planned for EOS/MODIS: International Journal of Remote Sensing.

Schier, M., ed.,.1993, The science objectives of the advanced spaceborne thermal emission and reflectance radiometer (ASTER): Jet Propulsion Laboratory, Pasadena, Calif, 19 p.

Schreier, G., and Muller, J.P., 1992, Global land one kilometer base elevation (GLOBE) project proposal - revision 3.0, $12 \mathrm{p}$.

Schwaller, M., 1993, Science data plan for the EOS data and information system covering EOSDIS version 0 and beyond - document version 2.0: NASA Goddard Space Flight Center, Greenbelt, Md, $67 \mathrm{p}$. 
Science Processing Support Office (SPSO), 1992, Earth Observing System output data products and input requirements - version 2.0 (3 volumes): NASA Goddard Space Flight Center, Greenbelt, Md.

Shimada, M., 1992, Topographic application of JERS-1 OPS stereo data: Proceedings of the Terrain Mapping Subgroup, Working Group on Calibration/ Validation, Committee on Earth Observation Satellites, Jet Propulsion Laboratory, Pasadena, Calif.

Space News, 1993, U.S. agencies seek mapping data from Pentagon: June 21, 1993.

Teillet, P.M., and Staenz, K., 1993, Atmospheric effects due to topography on MODIS vegetation index data simulated from AVIRIS imagery over mountainous terrain: Canadian Journal of Remote Sensing, v. 18, p. 283-292.

Topographic Science Working Group, 1988, Topographic science working group report to the Land Processes Branch, Earth Science and Applications Division, NASA Headquarters: Lunar and Planetary Institute, Houston, Texas, 64 p.

U.S. Geological Survey, 1990, Digital elevation models, data users guide 5: National Mapping Program Technical Instruction, $51 \mathrm{p}$.

Wivell, C.E., Steinwand, D.R., Kelly, G.G., and Meyer, D.J., 1992, Evaluation of terrain models for the geocoding and terrain correction of synthetic aperture radar (SAR) images: IEEE Transactions on Geoscience and Remote Sensing, v. 30, p. 1,137-1,144.

Wolf, M., and Wingham, D.J., 1992, A survey of the world's digital elevation data - Mullard Space Science Laboratory Report 4010/05-91/002: Mullard Space Science Laboratory, Dorking, Surrey, United Kingdom, 87 p.

World Climate Research Program (WCRP), 1991, Scientific plan for the GEWEX continentalscale international project (GCIP), $66 \mathrm{p}$. 


\section{Appendix 8.1 Accuracy Reporting for Topographic Data}

In any discussion of topographic data, both in specifying requirements and in describing data sets, it is important to use terminology correctly. The terms "resolution," "accuracy," and "precision" are sometimes used interchangeably, which is unfortunate because each represents a unique property of topographic data. Topographic data generally have two accuracies reported, horizontal and vertical.

The term resolution is sometimes used to refer to accuracy. Although they are clearly related, it is incorrect to equate the two. Resolution refers to the smallest unit that can be detected, or the smallest feature that is represented. For raster elevation models, the horizontal resolution may be referenced as the cell size, grid spacing, or posting interval. For instance, if a DEM has a horizontal resolution of 30 meters, the individual points in the data set that represent ground elevations are separated by 30 meters horizontally.

Accuracy describes how close a measurement is to truth. In other words, it relates the measurement to an established standard reference. Horizontal accuracy of topographic data is related to grid spacing. Because terrain features are generalized in the surface represented by a raster elevation model, it is difficult to measure the accuracy directly from a DEM to any greater degree than the grid spacing (U.S. Geological Survey, 1990). The horizontal accuracy reported for topographic data usually refers to the positional accuracy of features on the source material (image or map).

Horizontal accuracy can be reported as a statistical error probability. Circular error (C.E.) represents the probable maximum displacement of a point's horizontal position from its true position (combining errors in both the $\mathrm{X}$ and $\mathrm{Y}$ directions). The circular error is usually stated with a 90-percent confidence interval. This can be interpreted as follows: 90 percent of all points will meet or exceed the stated accuracy; or alternatively, for all points tested, 90 percent of the time the true location falls within a circle that has a radius equal to the stated accuracy and is centered on the grid location (Defense Mapping Agency, 1990). Circular error is most often found in accuracy statements for maps, although DMA also uses it to describe the accuracy of digital spatial data products (Defense Mapping Agency, 1986). Horizontal accuracy is also frequently reported as the mean error expressed as the root mean square error (RMSE). If the error distribution is Gaussian and has a mean of zero, the RMSE is equivalent to.the statistical standard deviation (or one sigma) of the measured errors. The RMSE is often used to report the locational error of geocorrected images. The horizontal measure reported for elevation data is usually absolute accuracy, which accounts for all systematic and random errors. Occasionally, point-to-point, or relative, accuracy is reported, which characterizes just the random errors within a specific data set.

For topographic data, vertical resolution is often confused with vertical accuracy. The vertical resolution, or sampling interval, of most elevation data sets is one unit of measure, (1 meter, 1 foot, or 1 centimeter). In other words, adjacent grid values may differ by as little as the vertical resolution, but this does not imply that an individual grid value is accurate to within 
that resolution. For example, a DEM can contain elevational differences as fine as 1 meter (the vertical resolution), but for any one grid point the actual terrain elevation at that location may differ by 7 meters (the vertical accuracy).

Vertical accuracy for topographic data relates the stated elevation to the true elevation with respect to a vertical datum, usually mean sea level. Vertical accuracy is often reported as linear error (L.E.) at the 90-percent confidence interval, or, stated otherwise, 90 percent of the points in a data set have a true elevation that is within \pm the given vertical accuracy. The RMSE has also been used to characterize vertical accuracy. However, if the error distribution is non-Gaussian, the RMSE may inadequately represent large error outliers. In these cases, reporting the "blunder rate," the percentage of points with elevation errors greater than three standard deviations from the mean error, may help to better describe the overall accuracy (Muller, Day, Upton, and Booth, 1992).

The vertical quality usually reported for elevation data is the absolute accuracy that includes all effects of systematic and random errors. For many applications, the point-to-point, or relative, accuracy within a certain data set is more important than the absolute accuracy. This relative accuracy has also been called the vertical precision, and it accounts for just the random error measurements in a data set. Studies of slope-dependent processes require very accurate slope measurements. Slope is usually calculated from raster elevation models by analyzing the local differences among adjacent grid points. Any random error contained in neighboring elevation measurements decreases the relative (point-to-point) accuracy and thus degrades any calculated slope. To better characterize the uncertainty of surface slope calculated from gridded elevation data, a measure of slope resolution can be used. The slope resolution is based on the horizontal resolution and the vertical precision. Slope between adjacent elevation points in a DEM cannot be calculated to any better accuracy than the slope resolution (Harding, 1992).

Figure 8.1-1 is a diagram of a hypothetical terrain surface, viewed as a profile, and the corresponding elevation model, shown as distinct points that represent the values of individual grid cells. Several characteristics of the elevation model are illustrated. The model has a horizontal resolution of 30 meters and a vertical resolution of 1 meter (measurement of differences in elevation between adjacent cells can be as fine as 1 meter). In this example, an absolute vertical accuracy of \pm 5 meters (linear error) is illustrated by the two points farthest to the left, and a relative vertical accuracy (point-to-point) of 2 meters is depicted with the two points farthest to the right.

The concept of spherical error has been used occasionally in an attempt to describe both the horizontal and vertical accuracies of a spatial data set with just one number. It can be thought of as a combination of linear error and circular error. Used with a confidence interval, it gives the probability of the true location of a feature, as defined by its true $X, Y ; Z$ coordinates, falling within a sphere that has a radius equal to the stated accuracy and is centered on the data point. 


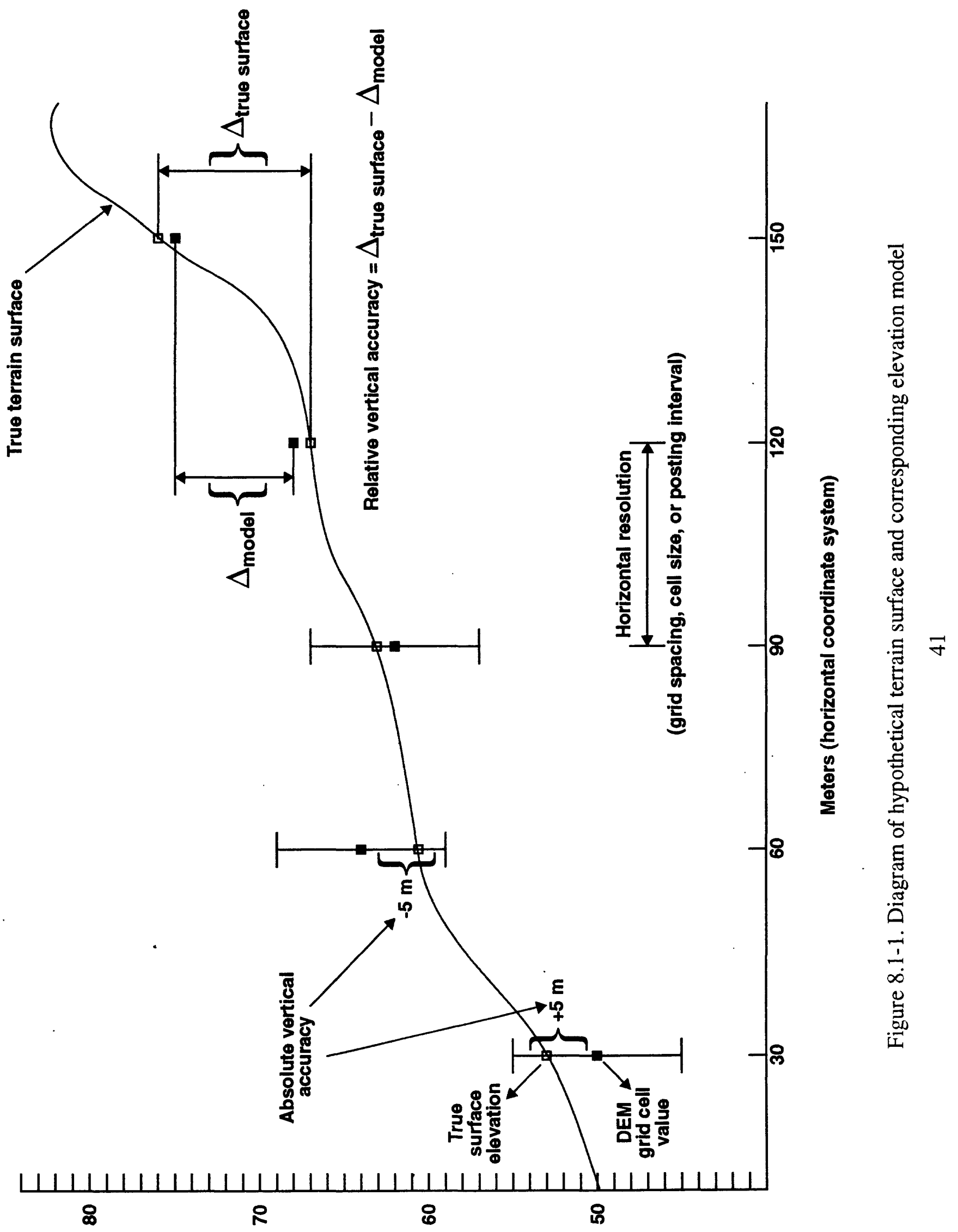

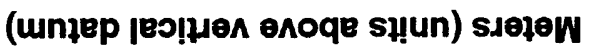


Consistent use of terms to refer to the accuracy of topographic data is important to correlate stated DEM requirements with existing or future data sets. Accuracy describes the overall quality of a measurement, where resolution and precision relate to the quality of the operation by which the measurement was obtained. It is also important to realize the distinction between describing accuracy with C.E./L.E. and RMSE metrics. The following properties should be listed to fully describe a topographic data set: horizontal resolution (grid spacing, cell size), absolute horizontal accuracy (C.E. or RMSE identified), absolute vertical accuracy (L.E. or RMSE identified), and, if known, the vertical precision. 


\section{Appendix 8.2 Digital Elevation Model Product Description}

The U.S. Geological Survey (USGS) offers several topographic data products under the name Digital Elevation Model (DEM).

\section{Product: 7.5-minute DEM}

Horizontal grid spacing: $\quad 30$ meters (referenced in UTM coordinate system)

Horizontal accuracy: $\quad 30$ meters (horizontal accuracy specification for 1:24,000scale cartographic source is 12 meters C.E. at 90 percent; horizontal accuracy specification for aerotriangulation of photographic source is 3 meters RMSE)

Vertical accuracy:

7 meters RMSE

Datum - horizontal

North American Datum of 1927 (NAD27) or North American Datum of 1983 (NAD83) in continental United States; Old Hawaiian Datum (OHD); Puerto Rico Datum of 1940 (PRD)

- vertical:

National Geodetic Vertical Datum of 1929 (NGVD29) for continental United States; local Mean Sea Level (MSL) in Hawaii and Puerto Rico

Coverage:

50 percent of continental United States; Hawaii; Puerto Rico

Source data:

1:24,000-scale contour overlays or NHAP/NAPP aerial photography

Distribution unit:

$7.5 \times 7.5$ minutes (matches USGS 7.5-minute map series quadrangle)

Producer:

USGS

Distributor:

USGS 


\section{Product: 7.5-minute Alaska DEM}

Horizontal grid spacing: $\quad 1$ arc second latitude $\times 2$ arc seconds longitude

Horizontal accuracy:

approximately 30 meters (horizontal accuracy specification for 1:24,000-scale cartographic source is 12 meters C.E. at 90 percent)

Vertical accuracy:

RMSE of one-half contour interval

Datum - horizontal:

NAD27 or NAD83

- vertical:

NGVD29

Coverage:

parts of Alaska

Source data:

1:24,000- and 1:25,000-scale contour overlays

Distribution unit:

$7.5 \times 10$ minutes (south of $59^{\circ}$ North latitude)

$7.5 \times 11.25$ minutes $\left(59^{\circ}-62^{\circ}\right.$ North latitude)

$7.5 \times 15$ minutes $\left(62^{\circ}-68^{\circ}\right.$ North latitude)

$7.5 \times 18$ minutes (north of $68^{\circ}$ North latitude)

Producer:

USGS

Distributor:

USGS 


\section{Product: 15-minute Alaska DEM}

Horizontal grid spacing: $\quad 2$ arc seconds latitude $\times 3$ arc seconds longitude

Horizontal accuracy: approximately 60 meters (horizontal accuracy specification for $1: 63,360$-scale cartographic source is 32 meters C.E. at 90 percent)

Vertical accuracy: $\quad$ RMSE of one-half contour interval

Datum - horizontal: $\quad$ NAD27 or NAD83

- vertical: $\quad$ NGVD29

Coverage: portions of Alaska

Source data:

$1: 63,360$-scale contour overlays

Distribution unit: $\quad 15 \times 20$ minutes (south of $59^{\circ}$ North latitude)

$15 \times 22.5$ minutes $\left(59^{\circ}-62^{\circ}\right.$ North latitude)

$15 \times 30$ minutes $\left(62^{\circ}-68^{\circ}\right.$ North latitude)

$15 \times 36$ minutes (north of $68^{\circ}$ North latitude)

Producer: $\quad$ USGS

Distributor: $\quad$ USGS 


\section{Product: 30-minute DEM}

Horizontal grid spacing:

Horizontal accuracy:

Vertical accuracy:

Datum - horizontal:

- vertical:

Coverage:

Source data:

Distribution unit:

Producer:

Distributor:
2 arc seconds latitude $\times 2$ arc seconds longitude

approximately 60 meters (horizontal accuracy specification for $1: 100,000$-scale cartographic source is 50 meters C.E. at 90 percent; horizontal accuracy specification for 1:24,000scale cartographic source is 12 meters C.E. at 90 percent)

RMSE of one-half contour interval

NAD27 or NAD83

NGVD29 in continental United States; local MSL in Hawaii Continental United States; Hawaii

1:100,000- and 1:24,000-scale contour overlays; existing 7.5minute DEM's

Four 15- x 15-minute DEM's covering a 30- x 30-minute area

USGS

USGS 


\section{Product: 1-degree DEM}

Horizontal grid spacing: $\quad 3$ arc seconds latitude $x 3$ arc seconds longitude in continental United States, Hawaii, and Puerto Rico; in Alaska: 3 arc seconds latitude $\times 6$ arc seconds longitude $\left(50^{\circ}-70^{\circ}\right.$ North latitude) and 3 arc seconds latitude $\times 9$ arc seconds longitude (north of $70^{\circ}$ North latitude)

Horizontal accuracy:

130 meters C.E. at 90 percent

Vertical accuracy:

\pm 30 meters L.E. at 90 percent

Datum - horizontal:

World Geodetic System 1972 Datum (WGS72) or World Geodetic System of 1984 (WGS84)

- vertical:

NGVD29 in continental United States and Alaska; local MSL in Hawaii and Puerto Rico

Coverage:

Continental United States; Alaska; Hawaii; Puerto Rico

Source data:

DMA DTED-1, 1:250,000-scale contour overlays, and photographic sources

Distribution unit: $\quad 1^{\circ} \times 1^{\circ}$

Producer: $\quad$ DMA and USGS

Distributor: USGS 


\section{Appendix 8.3 Digital Terrain Elevation Data Product Description}

The Defense Mapping Agency (DMA) has produced Digital Terrain Elevation Data Level 1 (DTED-1) for much of the global land surface, with coverage concentrated in the Northern Hemisphere.

\section{Product: DTED Level 1}

Horizontal grid spacing: $\quad 3$ arc second latitude spacing, longitude spacing varies by latitude zone:

$\begin{array}{cc}0^{\circ} \frac{\text { Latitude zone }}{50^{\circ} \text { North/South }} & \text { Grid spacing } \\ 50^{\circ}-70^{\circ} \text { North/South } & 3 \times 6 \text { seconds } \\ 70^{\circ}-75^{\circ} \text { North/South } & 3 \times 9 \text { seconds } \\ 75^{\circ}-80^{\circ} \text { North/South } & 3 \times 12 \text { seconds } \\ 80^{\circ}-90^{\circ} \text { North/South } & 3 \times 18 \text { seconds }\end{array}$

Horizontal accuracy:

130 meters C.E. at $90 \%$

Vertical accuracy:

\pm 30 meters L.E. at $90 \%$

Datum - horizontal:

World Geodetic System of 1984 (WGS84)

- vertical:

Mean Sea Level (MSL)

Coverage:

predominantly Northern Hemisphere

Source data:

1:250,000-scale contour overlays and photographic sources

Distribution unit:

$1^{\circ} \times 1^{\circ}$

Producer:

DMA

Distributor: .

DMA (worldwide data)

USGS (U.S. data)

EMR (Canada data)

INEGI (Mexico data)

Note:

Distribution of DTED for areas outside the United States, Canada, and Mexico is generally limited to organizations within the executive branch of the U.S. Government, and restrictions are also placed on publication of derived products and research results. 


\section{Appendix 8.4 Digital Chart of the World Product Description}

The Digital Chart of the World (DCW) is a vector data base digitized from the 1:1,000,000scale Operational Navigation Chart series. It includes all the cartographic and text features from the maps as different layers in a topologically structured data base. The DCW hypsography layers (contours and spot heights) and the drainage layers are the input for surface interpolation routines to generate gridded elevation data.

\section{Product: DCW grid}

Horizontal grid spacing: $\quad 30$ arc seconds (approximately $1 \mathrm{~km}$ )

Horizontal accuracy: $\quad 2,000$ meters C.E. at 90 percent (stated accuracy of DCW data base, accuracies for specific areas may be better; one test area had an accuracy of 583 meters C.E. at 90 percent)

Vertical accuracy: $\quad \pm 650$ meters L.E. at 90 percent (stated accuracy of DCW data base, accuracies for specific areas may be better; one test area had an accuracy of \pm 144 meters L.E. at 90 percent, another test area had an accuracy of 40 meters RMSE when compared against DTED, and a third area compared with DTED resulted in a 55meter RMSE; for many areas the expected accuracy is approximately 100 meters, or one-third of the primary contour interval)

Datum - horizontal: $\quad$ World Geodetic System of 1984 (WGS84)

- vertical: Mean Sea Level (MŚ)

Coverage:

near global coverage of hypsography source data; grids of Africa, North America, and South America projected for late 1994 availability

Source data:

DCW hypsography (contour interval of 1,000 feet, supplemental contours at 250-foot interval for elevations less than 1,000 feet, spot heights) and drainage data

Distribution unit: Continental and regional areas on CD-ROM

Producer:

USGS (DMA produced DCW vector data)

Distributor:

USGS 


\section{Appendix 8.5 Sources and Characteristics of Optical Stereo Data}

The sources described below are the satellite optical sensors that are, or will be, capable of collecting data suitable for generating topographic data to meet EOS requirements. Missing entries for a particular system parameter represent data that are either unknown or undetermined at this time.

Table 8.5-1 summarizes the important characteristics of the optical sensors. Included in the table for comparison purposes are the characteristics of some satellite SAR and laser sensors. Although it has now been deleted from the planned Landsat 7 sensor configuration, HRMSI is also included in the table for comparison purposes.

Sensor:

Platform:

Stereo acquisition mode:

Look angles:

Base-to-height ratio:

Nominal pixel size:

Swath width:

Vertical accuracy:

Horizontal accuracy:

Orbital altitude:

Orbital inclination:

Repeat cycle:

Equatorial crossing:

Launch date:

\section{HRV (panchromatic and multispectral)}

\section{SPOT}

cross track, repeat pass

$\pm 27^{\circ}$

$0-1$

10 meters (panchromatic); 20 meters (multispectral)

$60 \mathrm{~km}$

10 meters RMSE (panchromatic, with control)

10 meters RMSE (panchromatic, with control); 1,500 meters RMSE (without control)

$830 \mathrm{~km}$

$98.7^{\circ}$

26 days (2-day revisit with off-nadir cross-track pointing)

10:30 A.M.

1986 
Sensor:

Platform:

Stereo acquisition mode: along track, simultaneous

Look angles:

Base-to-height ratio:

Nominal pixel size:

Swath width:

Vertical accuracy:

Horizontal accuracy:

Orbital altitude:

Orbital inclination:

Repeat cycle:

Equatorial crossing:

Launch date:

\section{OPS}

\section{JERS-1}

nadir and $15.33^{\circ}$ forward

0.3

18 meters cross track $\times 24$ meters along track

$75 \mathrm{~km}$

60 meters RMSE

$568 \mathrm{~km}$

$97.7^{\circ}$

44 days

10:30 A.M.

1992 
Sensor:

Platform:

Stereo acquisition mode:

Look angles:

Base-to-height ratio:

Nominal pixel size:

Swath width:

Vertical accuracy:

Horizontal accuracy:

Orbital altitude:

Orbital inclination:

Repeat cycle:

Equatorial crossing:

Launch date:

\section{AVNIR}

ADEOS

cross track, repeat pass

$\pm 40^{\circ}$

0.6

$8 \mathrm{~m}$

$80 \mathrm{~km}$

$800 \mathrm{~km}$

$98.6^{\circ}$

41 days (1-day revisit with off-nadir cross-track pointing) 10:30 A.M.

1996 
Sensor:

Platform:

Stereo acquisition mode: along track, simultaneous or repeat pass;

Look angles:

Base-to-height ratio:

Nominal pixel size:

Swath width:

Vertical accuracy:

Horizontal accuracy:

Orbital altitude:

Orbital inclination:

Repeat cycle:

Equatorial crossing:

Launch date: cross track, repeat pass

\section{HRMSI}

originally planned for Landsat 7 but now deleted from the specified sensor package

$\pm 25^{\circ}$ along track, simultaneous;

$\pm 30^{\circ}$ along track, repeat pass;

$\pm 38^{\circ}$ cross track, repeat pass

$--$

$5 \mathrm{~m}$

$60 \mathrm{~km}$

\pm 17 meters L.E. at $90 \%$ (along track, without control)

23 meters C.E. at $90 \%$ (without control)

$705 \mathrm{~km}$

$98.2^{\circ}$

16 days (3-day revisit with off-nadir cross-track pointing)

9:45 A.M. 
Sensor:

Platform:

Stereo acquisition mode

Look angles:

Base-to-height ratio:

Nominal pixel size:

Swath width:

Vertical accuracy:

Horizontal accuracy:

Orbital altitude:

Orbital inclination:

Repeat cycle:

Equatorial crossing:

Launch date:

\section{ASTER}

\section{EOS-AM1}

along track, simultaneous;

cross track, repeat pass

nadir and $27.6^{\circ}$ backward viewing (along track, simultaneous); $\pm 24^{\circ}$ cross track (repeat pass)

0.6 (along track)

$15 \mathrm{~m}$

$60 \mathrm{~km}$

7-30 meters RMSE (along track, with control);

30-50 meters RMSE (along track, without control)

8-15 meters RMSE (with control)

$705 \mathrm{~km}$

$98.2^{\circ}$

16 days (5-day revisit with off-nadir cross-track pointing)

10:30 A.M.

1998 
Sensor:

Platform:

Stereo acquisition mode: along track, simultaneous

Look angles:

Base-to-height ratio:

Nominal pixel size:

Swath width:

Vertical accuracy:

Horizontal accuracy:

Orbital altitude:

Orbital inclination:

Repeat cycle:

Equatorial crossing:

Launch date:

\section{MISR}

\section{EOS-AM1}

nadir and $\pm 26.1^{\circ}$ forward and backward viewing

275 meters (off-nadir); 250 meters (nadir)

$364 \mathrm{~km}$

180 meters RMSE

$705 \mathrm{~km}$

$98.2^{\circ}$

9 days

10:30 A.M.

1998 


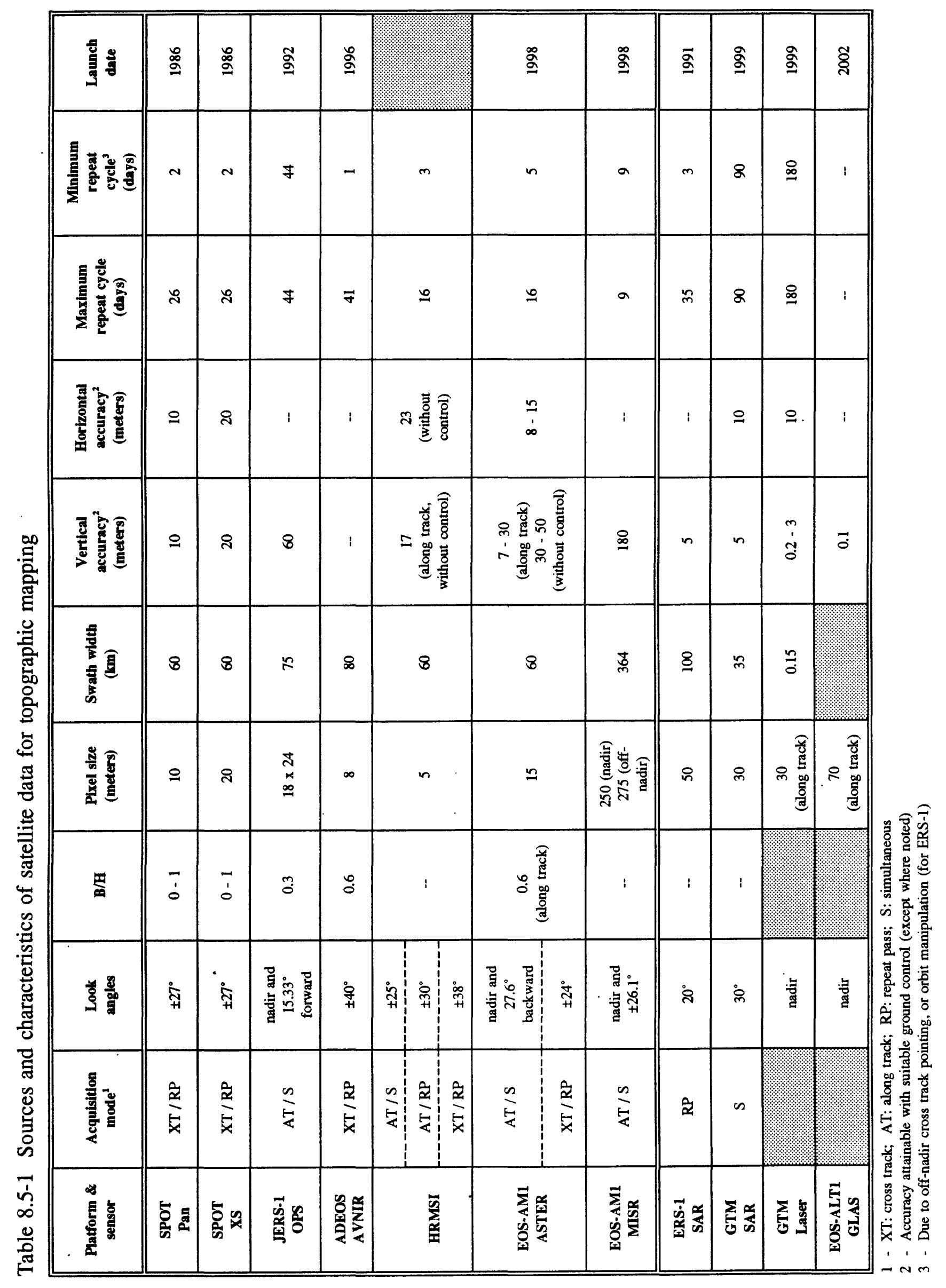




\section{Appendix 8.6 USGS Topographic Data Research Activities}

The USGS conducts an active research program in generating, using, and analyzing digital topographic data. The results of this program may be valuable for EOS investigators who are also using topographic data in their research. The use of topographic data and its derivatives for global change research is facilitated by the USGS demonstration of derivative product generation and elevation data usage.

The EROS Data Center (EDC) has developed capabilities to derive surface drainage information automatically from digital elevation data (Jenson and Domingue, 1988; Jenson, 1991). Drainage networks, watershed and subwatershed boundaries, flow directions, flow accumulations, and depressions are derived with EDC-developed software. This software has been widely distributed to the scientific community. An ongoing effort involves a comparison of automatically delineated networks with those from cartographic sources.

The use of topographic data for terrain correction of remote sensing images is an area of research at EDC that is applicable to EOSDIS. Wivell, Steinwand, Kelly, and Meyer (1992) have documented the effects of different levels of elevation data on geocoding and terrain correction of SAR images. The Canadian Center for Remote Sensing (CCRS) has developed similar techniques for analyzing the effect of topographic data on SAR processing (Guindon, 1993), and plans call for cooperative work between EDC and CCRS to better characterize the DEM requirements for geocoding sensor data over North America.

The EDC is also investigating the use topographic data for improved insolation modeling. The radiometric correction of images will benefit if the effects of slope, aspect, and atmospheric path length, which can be derived from elevation models, are better understood. The EDC is also examining the capabilities of remote sensing systems for generating elevation data. Terrain models derived from SPOT stereo images have been evaluated, and JERS-1 optical stereo images will be processed to derive an elevation model that can be evaluated.

The USGS is conducting other DEM-related research, and the EDC serves as a transfer agent so that any advances made by the USGS in terrain modeling can be applied to help solve EOSDIS topographic data issues. This research includes an examination of different digital correlation techniques to automatically extract elevation data from stereo images (Acevedo, Mathiasmeir, and Norvelle, 1993) and a comparison of photogrammetrically derived elevation data with that derived from interferometric SAR data. Additional topics being addressed by USGS researchers include enhancing contour-to-grid interpolation procedures used in USGS DEM production, evaluating new, alternative gridding procedures, analyzing data generalization methods and their effect on derivative products, and development of improved shaded-relief map generation techniques. 


\section{Appendix 8.7 Distribution of Topographic Data}

The various topographic data sets described in this report are distributed by several organizations. Distribution information is provided below.

\section{Organization: $\quad$ U.S. Geological Survey}

Products: $\quad$ DEM, DCW, DLG

Address: $\quad$ EROS Data Center

Customer Services Section

Sioux Falls, SD 57198

(605)594-6151

FAX (605)594-6589

or

1-800-USA-MAPS to order through one of 10 USGS Earth Science Information Centers (ESIC)

or

Data availability and ordering information can be obtained through the Global Land Information System (GLIS), an interactive computer system that is accessed through wide-area networks and dial-up telecommunications interfaces. GLIS can be accessed in one of the following ways:

from INTERNET: telnet glis.cr.usgs.gov

or

telnet 152.61 .192 .54

from NSI/DECNET: SET HOST GLIS

USERNAME: GLIS

by modem: (605)594-6888 (8 bits, no parity, 1 stop bit)

Further information on GLIS can be obtained from:

EROS Data Center

GLIS User Assistance

Sioux Falls, SD 57198 (or call 1-800-252-GLIS) 
Organization: National Oceanic and Atmospheric Administration

Products:

ETOPO5 (and other coarse-resolution topography data bases)

Address: $\quad$ National Geophysical Data Center

NOAA, Code E/GC4

325 Broadway

Boulder, CO 80303-3328

(303) $497-6338$

FAX (303)497-6513

INTERNET info@mail.ngdc.noaa.gov

Organization: Defense Mapping Agency

Products: $\quad$ DTED

Address: $\quad$ Director

DMA Headquarters

ATTN: PR

8613 Lee Highway

Fairfax, VA 22031-2137

(703)285-9300

Organization: Energy, Mines and Resources Canada

Products: $\quad$ DTED, digital hypsography data, DCW

Address: $\quad$ Products and Services Division

. Surveys, Mapping and Remote Sensing Sector

Energy Mines and Resources Canada

615 Booth St., Room 400

Ottawa, Ontario K1A 0E4

CANADA

(613)995-2123

FAX (613)995-6001 
Organization: National Institute for Statistics, Geography, and Information (INEGI)

Products: $\quad$ DTED

Address: $\quad$ Servicio a Usarios

INEGI, Direccion de Integracion y Analisis

Subdireccion de Comercializacion

Heroe de Nacozari 2301 Puerta 11

Col. del Parque C.P. 20290

Aguascalientes, AGS

MEXICO

52-49-181948

FAX 52-49-180739

A valuable listing of other organizations that produce and distribute topographic data for various areas of the world is found in:

Wolf, M., and Wingham, D.J., 1992, A survey of the world's digital elevation data - Mullard Space Science Laboratory Report 4010/05-91/002: Mullard Space Science Laboratory, Dorking, Surrey, United Kingdom, 87 p. 